Portland State University

PDXScholar

$11-25-1981$

\title{
Affective Perspective-Taking and Sympathy in Young Children
}

Mary Driver Leinbach

Portland State University

Follow this and additional works at: https://pdxscholar.library.pdx.edu/open_access_etds

Digitalrt of the Child Psychology Commons, and the Cognitive Psychology Commons cemenen know how access to this document benefits you. Network

\section{Logo \\ Recommended Citation}

Leinbach, Mary Driver, "Affective Perspective-Taking and Sympathy in Young Children" (1981).

Dissertations and Theses. Paper 3066.

https://doi.org/10.15760/etd.3060

This Thesis is brought to you for free and open access. It has been accepted for inclusion in Dissertations and Theses by an authorized administrator of PDXScholar. Please contact us if we can make this document more accessible: pdxscholar@pdx.edu. 
AN ABSTRACT OF THE THESIS OF Mary Driver Leinbach for the Master of Arts in Psychology presented November 25, 1981.

Title: Affective Perspective-Taking and Sympathy in Young Children APPROVED BY MEMBERS OF THE THESIS COMMITTEE

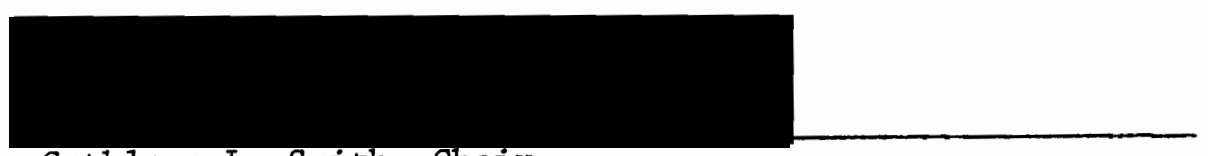

Cathleen L. Smith, Chair

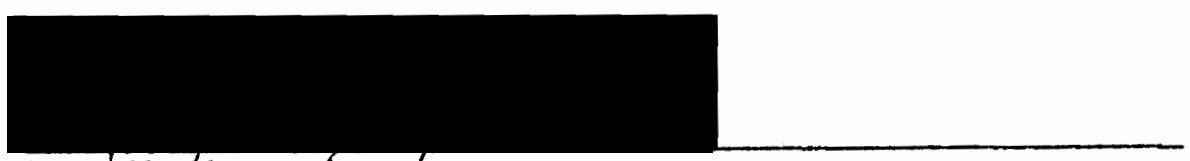
Hugo M. Maynard

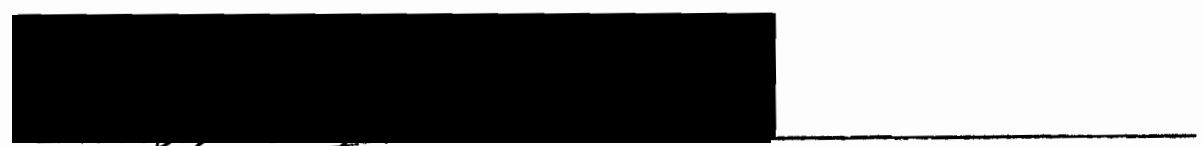

Sydney Reisblek

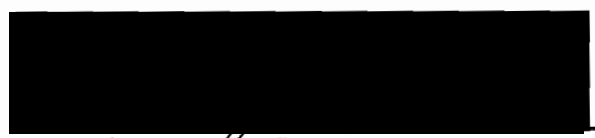

Barbara \$. Stewart

The present study focused upon both behavioral and cognitive aspects of sympathetic responses in preschool children. Subjects, 36 boys and girls aged 33-75 months, were seen at their regular day care center. An attempt was made to promote comforting behavior through the use of a peer model both alone and accompanied by an adult's inductive statement regarding the consequences of a sympathetic response; a six year-old girl served as the sympathetic model and as an apparently injured victim in need of comforting. In addition, age- and sex-related relationships for the measures of social cognition, affective perspec- 
tive-taking and knowledge of strategies for intervening when another person's plight invites sympathetic concern, were examined. The former measure employed a commonly used task presenting children with picture stories in which a target character's facial expression is not congruent with information provided by the story situation. Such stimuli have been thought to assess the ability to assume the emotional point of view of a particular person (empathic judgment), as opposed to the egocentric projection of one's own perspective onto another (projective judgment). Capacities for recognizing and explaining situationally consistent emotions (social comprehension and explanation of affect) and explaining the incongruent facial and situational cues (awareness of discrepancy) were also evaluated. The psychometric properties of these measures were a major concern; consequently, internal consistency reliability as well as age- and sex-related differences among item means, which were presumed to reflect differences in item difficulty, were examined for each component of both measures. Finally, relationships among all measures were examined.

Neither observing the peer model's sympathetic response nor hearing it labeled and approved by an adult was effective in promoting a comforting response to the model's feigned injury. Consequently, the experimental groups were combined and the scores used in the correlational investigation of relationships among measures. All parts of the two cognitive measures except empathic and projective judgments were significantly intercorrelated and strongly related to age, and these relationships remained strong when age was partialled out. Girls made more projective judgments than did boys. There were no age differences 
for empathic judgment, but younger boys made more projective judgments than older boys.

These results challenge the use of incongruent facial and situational stimuli as a measure of perspective-taking, provide evidence of young children's capacities for sympathetic thought and behavior and their understanding of others' emotions, and both raise and illuminate methodological questions concerning social-cognttive measures of the type used in this study. 
AFFECTIVE PERSPECTIVE-TAKING AND SYMPATHY IN YOUNG CHILDREN

by

MARY DRIVER LEINBACH

A thesis submitted in partial fulfillment of the requirements for the degree of

MASTER OF ARTS

in

PSYCHOLOGY

Portland State University 
TO THE OFFICE OF GRADUATE STUDIES AND RESEARCH:

The members of the Committee approve the thesis of Mary Driver Leinbach presented November 25, 1981.
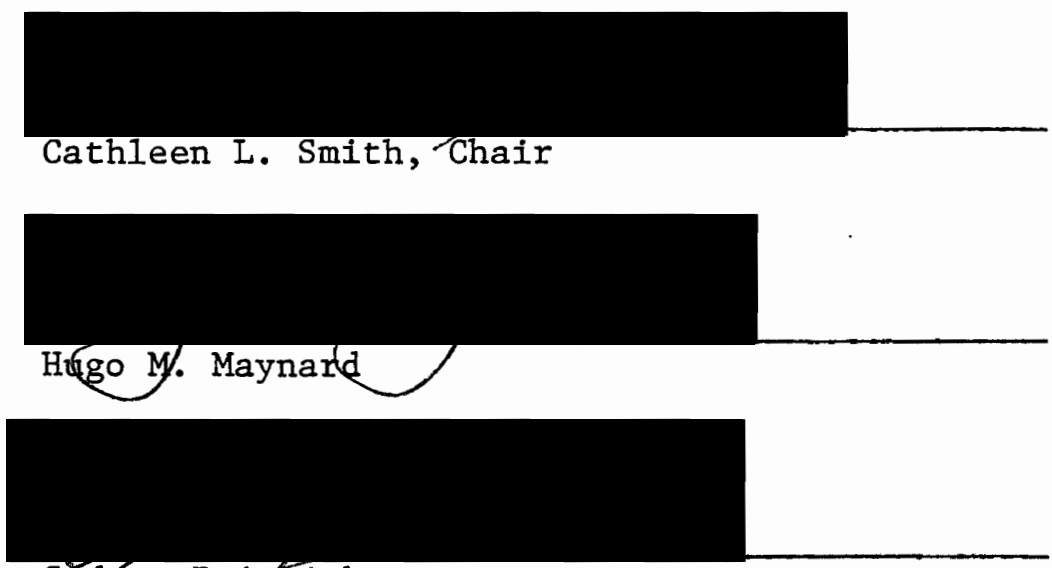
Sydhey Reisbick

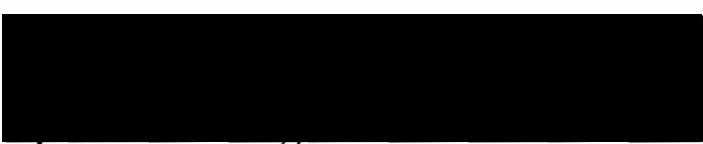

Barbara J. \&tewart

\section{APPROVED :}

David wrench, Head, Department of Psychology

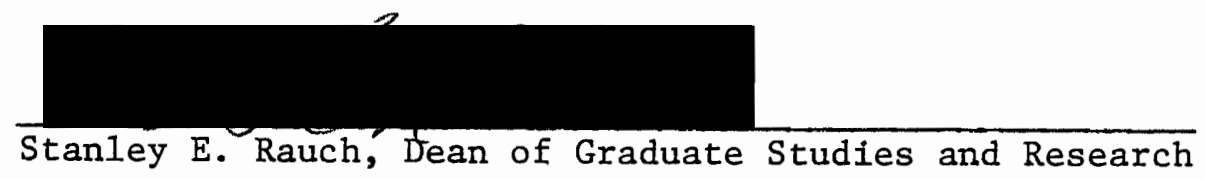




\section{ACKNOWLEDGEMENTS}

I would like to express my appreciation for the assistance and support of the many people who made this study possible:

To my adviser and committee chair, Dr. Cathleen L. Smith, and to the other members of my committee, Dr. Hugo M. Maynard, Dr. Sydney Reisbick, and Dr. Barbara J. Stewart, each of whom has contributed in his or her own special way not only to the accomplishment of this study but to my life and to my career as a student. I am truly grateful for their continued guidance and encouragement.

To Carol Dendurent, Director of the Canterbury Learning Tree Day School, who was more than generous with her time and organizational skill; to the teachers, staff, and parents for their help and cooperation; and especially to the children who served as subjects--the memory of their charm and candor delights me still.

To Rebecca Ariens, the child confederate upon whose six year-old shoulders so much responsibility for this study was placed. No adult could have turned in a finer or more consistent performance; Becca was the star of the whole procedure.

To Karin Ariens and Jane Blackwe11, who were involved in every phase of this study from beginning to end. Karin's performance as the second experimenter was faultless, and Jane took on much of the responsibility for the observational data. With Jane and Karin, under the direction of Cathy Smith and Barbara Stewart, I learned the value of teamwork in research. 
Finally, to my family and friends, and especially to my husband, whose help and emotional support have made it possible for me to pursue my graduate education.

I thank you. 


\section{LIST OF TABLES}

TABLE

PAGE

I Overview of the Three Sessions and Measures Obtained . . . 22

II List of Variables with Derivations and Possible Ranges of Scores . . . . . . . . . . . . . . . 29

III Means and Standard Deviations for Task 1, Task 2, and Behavioral Measures, and Age . . . . . . . . 34

IV Intercorrelations Among Al1 Task 1 and Task 2 Measures, Behavioral Measures, and Age . . . . . . . . 40 


\section{LIST OF FIGURES}

FIGURE

PAGE

1. Sample congruent and incongruent items from Task 1 . . . . 24

2. Sample item from Task 2 . . . . . . . . . . . 26 
TABLE OF CONTENTS

PAGE

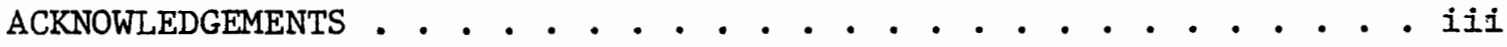

LIST OF TABLES . . . . . . . . . . . . . . . . . . . . viii

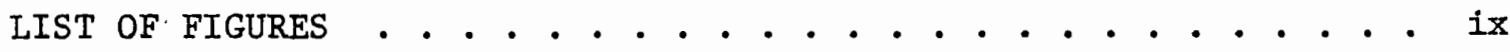

CHAPTER

I INTRODUCTION • . . . . . . . . . . . . . . . . 1

Perspective-taking: Assuming. Another's Point of View. 4

Affective Perspective-Taking

Measuring Affective Perspective-Taking: The Incongruent Items Paradigm

Relating Perspective-Taking Measures to Prosocial Behavior

Sympathetic Behavior (Comforting) . . . . . . . 12

Training Children in Sympathetic Behavior . . . . . 14

The Use of Models

Induction

Sex and Age Differences . . . . . . . . . 17

Overview of the Present Study . . . . . . . 17

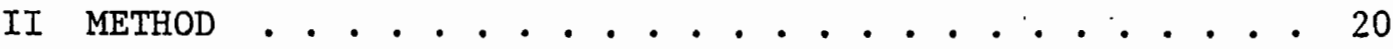

Setting . . . . . . . . . . . . . . 20

Subjects . . . . . . . . . . . 20

Procedure . . . . . . . . . . . . . 20

Session 1

Session 2

Session 3 
Scoring

Behavioral Measures

Cognitive Measures

Reliability ................... 31

Data Analysis ................ 31

Behavioral Measures

Item Analyses

Relationships Among Measures

III RESULTS . . . . . . . . . . . . . . . . 33

Behavioral Measures ... . . . . . . . 33

Item Analyses . . . . . . . . . . . . 35

Task 1

Task 2

Internal Consistency Reliability

Sex and Age Differences . . . . . . . . . . 38

Relationships Among Measures . . . . . . . . 39

IV DISCUSSION . . . . . . . . . . . . . . . 42

BIBLIOGRAPHY . . . . . . . . . . . . . . . . . 57 APPENDICES

A Stimulus Materials . . . . . . . . . . . 62

Response Faces ................ 63

Task 1 Items ................ . 64

Congruent Items

Incongruent Items

Task 2 Items ................. 70

B Scripts for the Three Experimental Conditions . . . . . 75 
C Scoring Systems . . . . . . . . . . . . . 77

Scoring System for Sympathetic Behavior . . . . . . 78

Scoring System for Explanation of Affect and Awareness of Discrepancy . . . . . . . . . . 79

Scoring System for Intervention Strategies . . . . . 80

D Analysis of Variance Summaries . . . . . . . . . . 81

Analysis of Variance Summary for Comforting Behavior . 81

Analysis of Variance. Summary for Reporting the Child

Confederate's Injury . . . . . . . . . . . . 82

E Item Analyses . . . . . . . . . . . . . . . 83

Item Intercorrelations for the Five Task 1 Measures. . 84

Item Intercorrelations for the Two Task 2 Measures . . 85

Summary of Significant F Values for Task 1 and

Task 2 Repeated Measures Analyses of Variance . . . 86 
CHAPTER I

\section{INTRODUCTION}

In everyday life, the kinds of behavior which smooth interpersonal relationships and contribute to the development of social consciousness tend to go unnoticed, while violently aggressive acts are reported far and wide. This tendency has been reflected in the psychological literature dealing with children's behavior, where studies of aggression have in the past far exceeded investigations of altruistic and prosocial activity. Currently, the need for a more thorough understanding of the ways in which positive behaviors of all kinds are acquired, and the conditions under which they are expressed, has become apparent, and the past few years have seen a surge of interest in children's prosocial actions. Sympathetic behavior, the offering of comfort or condolence to another person, is an aspect of children's prosocial interpersonal behavior which has received little empirical attention, although studies of empathy, which is often thought to underlie the expression of sympathy, are not uncommon. The investigation of empathy in children, however, has involved a controversy regarding the age at which children are capable of assuming the role or perspective of another person. The present experiment was designed to examine. measures of affective role- or perspective-taking and children's ability to verbalize appropriate responses to others' distress, to investigate the influence of modeling and verbal elaboration of consequences upon 
sympathetic behavior (comforting) in children, and to assess relationships among these cognitive and behavioral measures.

Traditional psychological descriptions of the young child suggest a completely egocentric organism, bent on gratifying its own desires and oblivious to the needs of others. Yet anecdotal 1iterature abounds with incidents which would seem to contradict so bleak a view, as do a few early observational studies. In one of these, Murphy (1937), observing the free play of nursery school children, found that they were quite capable of acts of helping, sharing, comforting, and defending, and, while these were not high-frequency behaviors, they did occur spontaneously (i.e., without prompting from adults). She also found that children who were most inclined to exhibit these behaviors, which together she called sympathy, were also more inclined to express aggression; in her sample, aggressive incidents outnumbered prosocial acts by eight to one. Though Murphy's study has been mentioned frequently, usually in connection with the unexpected association between sympathy and aggression, for more than twenty years little interest was shown in investigating the questions she raised. The recent decade, however, has seen a renewal of interest in prosocial and altruistic behavior, and in the processes by which human beings become sensitive to the concerns of others and willing to exert themselves in another's behalf. Satisfactory explanation for altruistic and prosocial behavior has not proven easy to come by. Both terms refer to behavior that is carried out for the benefit of another person (Rushton, 1976), but for altruism the stipulation is usually added that the act be voluntary and involve some element of self-sacrifice (Wispe, 1978), or at least that there be no expectation of gain for the actor (e.g., Krebs, 1970; 
Hoffman, 1976; Staub, 1978). Prosocial behavior is generally defined in terms of its effect for the recipient ("behavior which benefits other people," [Staub, 1978, p. 2]) which ignores but does not resolve the question of motivation, but the proscription against reward is sometimes added (e.g., Mussen \& Eisenberg-Berg, 1977). The terms are often used interchangeably even though, as Staub pointed out, behavior which benefits others may or may not be altruistically motivated. Still, in everyday life we do see acts which seem to fit the definition of altruism. Since altruistic behavior does not appear to be associated with a state of deprivation or need in the actor, nor, by definition, with extrinsic reward, the impetus toward such behavior and the reinforcement which sustains it are not easily specified.

Empathy, or responsiveness to others' emotions, has in fact been proposed as a motivational factor underlying various forms of altruistic behavior (e.g., Feshbach, 1975; Hoffman, 1975, 1981; Iannotti, 1975b; Mussen \& Eisenberg-Berg, 1977), and as a specific prerequisite of sympathetic distress (Hoffman, 1978). However, research on empathy in children has been clouded by inconsistency in defining the term. While some investigators see empathy as a cognitive response and are concerned with the child's recognition and understanding of another's feelings, others require, instead or in addition, an emotional response. Yet even where empathy is considered primarily an emotional response to others' affect, the importance of cognitive processes in recognizing and understanding emotion is acknowledged. It is with these cognitive aspects of empathic responding that this study is concerned. 
PERSPECTIVE-TAKING: ASSUMING ANOTHER'S POINT OF VIEW

Investigations of children's ability to understand the emotions of others have been carried out against the background of Piaget's characterization of preoperational children as egocentric, trapped within their own subjective experience and unable to assume the perspectives of other people (e.g., Piaget, 1923/1959; Piaget \& Inhelder, 1948/1956). Viewed in this way, the child's cognitive development involves progressive structural change from early egocentrism to the mature ability to put one's self in another's place, to infer the subjective experience of the other person. Consequently, much of the research concerning egocentrism in children has investigated the ability to take another's point of view (i.e., role- or perspective-taking, which has been considered the converse of egocentrism [Ford, 1979]), and has questioned when or whether children can make non-egocentric judgments or charted developmental changes in their ability to do so. Selman (1980), for example, has proposed a stage model of interpersonal understanding based upon children's ability to distinguish the alternative perspectives held by characters in filmed vignettes involving socio-moral dilemmas. Turiel (1978), noting the wide range of ages at which children can succeed at various perspective-taking tasks, considers this ability a "method" or way of obtaining information, rather than a "structural-developmental dimension" (p. 102) of the child's thought. In his view, children construct conceptual frameworks or ways of organizing their understanding of the world which change qualitatively as development proceeds and interaction with the environment occurs. As the level of conceptual development advances, the child will 
be able to apply information-gathering methods such as perspectivetaking to material of greater variety and complexity.

The preceding views of perspective-taking suggest a unitary dimension or skill, but other researchers have distinguished among perceptual, cognitive, and affective aspects of this ability. That is, one may ask, respectively, what another sees, knows, or feels, and perspective-taking tasks have been categorized according to these distinctions. While such separations run counter to Piaget's concept of the child as a structural whole (Chandler, 1977), a number of studies have attempted to understand children's interpersonal behavior in terms of the ability to assume the emotional perspectives of others.

\section{Affective Perspective-Taking}

Taking the affective perspective of another person involves mentally placing one's self in another's emotional situation, and must necessarily include recognition of that person's emotional state. Even three year-olds may display this basic ability (Borke, 1971), and children as young as four or five show consensus in their expectancies with regard to the affective outcomes of various experiences (Barden, Zelko, Duncan, \& Masters, 1980).

Borke (1971) asked subjects to identify drawings of four faces whose expressions indicated happiness, sadness, anger, or fear. Eight stories were then told in which a child could be perceived as feeling these emotions. Each story was accompanied by a picture of a child with a blank face, and the subject was asked to complete the picture by selecting the face which best showed how the child in the story felt. Not only could children as young as three years of age identify 
pictures of faces as happy or sad, they could point to the correct faces to accompany stories for which these emotions would be appropriate. (Subjects were also asked why the story character felt the emotion which had been specified, but results of this line of inquiry have not yet been published.) Borke concluded that detecting young children's capacity for empathic responses, that is, their understanding of what others are feeling, requires an essentially non-verbal task, and that her results called into question the notion that children are egocentric and unable to adopt the point of view of another person.

Borke's (1971) position was challenged on the grounds that affect recognition, though necessary, is not sufficient as evidence against egocentrism (Chandler \& Greenspan, 1972). Since even young children tend to agree about emotional expressions and their situational referents, there is really no way to determine in the ordinary course of events whether another person's affective state has been perceived accurately. In particular, one's own probable emotion in a comparable situation, or the most likely response of people in general, may have been attributed to the other person. These latter responses have been designated projective and normative judgments, respectively. Only empathic judgment, the accurate identification of the feelings of specific others, entails assuming another's emotional perspective. Projecting one's own probable reaction onto another is considered an egocentric response. And while not necessarily egocentric, a normative judgment based upon knowledge of how most people would feel in a given situation is generally not considered empathic (Shantz, 1975). Thus, it would seem impossible to distinguish empathic judgments from those which are projective or normative except in situations where the emotion 
displayed is not what would ordinarily be expected in that situation.

Measuring Affective Perspective-Taking: The Incongruent Items Paradigm

In one approach to the problem of identifying non-egocentric responses to others' emotions, children are shown drawings, photographs, or video-taped episodes depicting a character whose facial expression is at odds with the rest of the information given (Burns \& Cavey, 1957; Greenspan, Barenboim, \& Chandler, 1976; Kurdek \& Rodgon, 1975; Urberg \& Docherty, 1976; Iannotti, 1975a). In one of Burns and Cavey's picture stories, for example, a child is shown smiling despite the approach of a doctor wielding an oversized hypodermic syringe. The subject is thought to have assumed the target character's affective perspective if the character's emotion is specified on the basis of the facial expression despite the pull of situational cues; reliance on situational cues is considered projective or simply wrong. (This paradigm has also been used to assess empathy as an affective response, with the subject's professed affect considered empathic if it coincides with the facial expression shown, rather than the situationally appropriate emotion [Iannotti, 1978]).

Gove and Keating (1979) used a modified version of the incongruent items paradigm in which differing facial expressions dictated that an event was objectively the same but subjectively different for each of two characters (e.g., each receives a puppy, but one child is smiling while the other appears sad). Gove and Keating saw situational inferences, which would be considered projective in the studies described earlier, as indicating that for young children emotions are not differentiated from the situations which elicit them; that is, feelings, 
actions, and context are all of a piece. On the other hand, psychological (i.e., inference based on the characters' inner states) inference would require appreciation that people in a given situation do not necessarily react in the same ways; recognition of the differing emotions was thought to show awareness that particular emotions are not inextricably bound to certain situations.

Unfortunately, use of the incongruent items paradigm has yielded no clear developmental insight regarding children's ability to make affective judgments. While Burns and Gavey (1957) found that five and six year-olds were more likely than children under five to use the facial expression in judging the target character's affect, in Kurdek and Rodgon's (1975) kindergarten through sixth grade sample projection was more prevalent at higher grade levels. Iannotti (1975a) found no relationship between age and naming the character's emotion on the basis of either facial expression or situational information. Greenspan et al. (1976) presented first and third grade children with a brief videotaped sequence in which one adult male decisively beat another in an arm-wrestling contest. One version of the tape ended with the loser looking and sounding appropriately sad; in the incongruent version, he appeared nonchalant and smiling while admitting his loss. Nearly all of the children from both grades who saw the incongruent videotape described the loser as having negative affect, although the older ones indicating more uncertainty about their judgments. However, when asked to describe the character's facial expression, the older children correctly identified it as positive, while almost two-thirds of the younger children incorrectly specified a negative emotion. Gove and Keating (1979) found that older children (mean age, 62 months) were 
better than younger ones (mean age, 46 months) at discriminating the different emotions displayed by two characters in the same situation, as well as more likely to base their judgments on intrapersonal rather than situational explanations.

Relating Perspective-Taking Measures to Prosocial Behavior

Given the preceding pattern of results, it is hardly surprising that performance on affective perspective-taking tasks has not consistently been found to be related to prosocial behavior. Strayer (1980) found children's naturally-occurring helping, comforting, and giving positive reinforcement "modestly" (p. 821), albeit not significantly, related to their performance on two measures of perspective-taking (one of which used the incongruent items paradigm). Performance on these measures was also unrelated to a measure of donations to a poor child. Iannotti (1975a) found no relationship between the use of either facial or situational cues in judging a story character's emotion and the number of candies children shared with an absent needy child. On the other hand, Buckley, Siegel, and Ness (1979) found a positive relationship between scores on a measure similar to that used by Borke (1971) and children's helping and sharing. Zahn-Waxler, Radke-Yarrow, and Brady-Smith (1977) compared perspective-taking ability with measures of helping, sharing, and comforting obtained from an earlier study (Yarrow \& Waxler, 1976), and concluded that understanding of perspectives did not predict prosocial behavior. However, Zahn-Waxler et al. employed tasks which dealt specifically with questions of what other people see and hear or what they might be expected to think or prefer (e.g., the ability to choose an appropriate gift for an adult or an 
opposite sex peer); an affective perspective-taking task might have been a more appropriate choice if indeed it is reasonable to expect that accurate perception of others' feelings will enhance the probability of treating people well. So far, evidence for this notion has been equivocal where children are concerned.

The inconsistent findings with respect to the incongruent items paradigm indicate several possible methodological and conceptual problems. First, the few studies which have assessed the construct validity and internal consistency of affective perspective-taking measures have not been encouraging (Ford, 1979; Kurdek, 1978; Rubin, 1978). In addition, a forced choice between facial expression and situational information in specifying another's emotion may indicate too narrow a conceptualization of the ability to understand others' emotions. It is at least necessary to determine what such a choice means for the child, and to do this the reasoning process behind the response must be considered. Furthermore, the ability to integrate both expressive and situational cues is unlikely to be related only to a decline in egocentrism, but may instead reflect improvement in the capacity for attending and processing information in general. Children may fail at perspective-taking tasks for reasons that have little to do with the ability to escape one's own outlook and take another's point of view (Borke, 1971; Ford, 1979). A task may be too complex, or the content too unfamiliar for the child to understand; such failures are not solely attributable to egocentrism as a limitation in cognitive structure, although they may be accommodated within Turiel's (1978) definition of perspective-taking as a way of obtaining information. 
Moreover, attempts to relate measures of perspective-taking to prosocial behavior encounter problems in selecting an appropriate criterion response. Differences in the frequency and presentation of events which invite prosocial responses, as well as in expected base rates for various behaviors, undoubtedly contribute to inconsistent findings. Available normative data indicate that young children's prosocial acts such as helping, sharing, and especially comforting are relatively infrequent occurrences (Eisenberg-Berg \& Lennon, 1980; Murphy, 1937; Yarrow \&.Waxler, 1976). Consequent1y, if one wishes to study such behaviors solely as they occur in natural settings, the dross rate (i.e., the ratio of irrelevant material to useful information [Webb, Campbe11, Schwartz, \& Sechrest, 1966]) may be somewhat high. More importantly, since prosocial acts are most 1ikely to occur in response to events rendering another person in need, field observations may not fully take into account differences in opportunity to engage in the target behaviors. Hence, comparisons of rates of occurrence per unit of observation across subjects or behavioral categories defy meaningful interpretation. Strayer (1980), in reporting prosocial and "empathic" behaviors as proportions of observed affect displays to which subjects responded, has begun to deal with this problem; her work represents an important corrective to methodology in this area. Differential opportunity to display particular behaviors can also be controlled by presenting natural-appearing eliciting events uniformly to all subjects (e.g., Buckley, Siegel, \& Ness, 1979; Yarrow \& Waxler, 1976). Such structured observations provide a useful and reasonable adjunct to observations of naturally occurring behavior, provided the simulation represents an adequate approximation of events 
in a natural context.

SYMPATHETIC BEHAVIOR (COMFORTING)

Of the various prosocial behaviors which might be investigated with regard to perspective-taking, sympathetic behavior (i.e., the offering of comfort or condolence to another person in distress) seems particularly relevant. Although the cognitive and emotional underpinnings of comforting behavior are not clear, some degree of understanding of another's predicament must precede intervention on the other's behalf. In order for a sympathetic response to be elicited, the distress of another person must occur and be recognized, and the respondent must not only have an appropriate course of action at his or her disposal, but be motivated to produce it. However, little is known about children's understanding of other people's mishaps and what might be done to alleviate another's distress.

Children's attempts to comfort another person appear to be rare, but they do occur occasionally. (e.g., Eisenberg-Berg \& Lennon, 1980). These responses, however, have seldom been studied experimentally. Yarrow and Waxler (1976) carried out one of the most extensive investigations to date of the incidence of helping, sharing, and sympathetic behavior (comforting), in both naturally occurring situations and in response to contrived opportunities in a laboratory setting. In the naturalistic investigation, each of 77 nursery school children was observed in four 10-minute samples of free play, and $87 \%$ of them exhibited at least one prosocial act. Sharing and comforting (these categories were combined because of low frequencies) occurred, on the average, 2.1 times per child, and helping acts 6.2 times in each 40minute sample of behavior. Laboratory measures of these behaviørs were 
obtained from 108 children aged three to seven and a half, including the nursery school children mentioned above. The children were seen individually in two 40-minute sessions, in which six situations inviting helping, sharing, and comforting responses were blended into naturalistic social interaction with one or two female adults. In the tests of sharing, the child was given food or a toy, while one of the adults was deprived. Opportunities to help involved picking up materials dropped by an adult. In the two tests of comforting, both physical and emotional distress were displayed. In one, the experimenter pinched her finger in a drawer, grimaced and held her hand, and then went to run cold water on $i t$. On the other occasion, the child was left alone briefly and another female adult reading in a distant part of the room began to cry, supposedly over a sad story. There was "audible sniffling, trembling breathing, and soft sobbing" (p. 120) lasting about one minute. In all of these incidents a prosocial response was scored if the subject intervened actively to give aid; $80 \%$ of the children did so in at least one of the six situations. Prosocial responses to at least one of the helping tasks were given by $52 \%$ of the children, $33 \%$ responded prosocially to at least one of the sharing tasks, and $37 \%$ to one or both opportunities to give comfort.

The problem of inconsistency in the presentation of eliciting events makes Yarrow and Waxler's (1976) naturalistic data difficult to interpret, since the infrequency of comforting behavior may have been due to a dearth of victims in need of consolation. However, although comforting and sharing were less common than helping in both the natural and structured settings; quite a few children shared and offered comfort when given the opportunity to do so. 
TRAINING CHILDREN IN SYMPATHETIC BEHAVIOR

The Use of Models

Although there have been many attempts to measure the empathic capabilities of young children, few efforts have been made to train children to behave sympathetically. Recent investigations of prosocial behavior have produced impressive evidence for the efficacy of modeling procedures in promoting altruistic behavior in children, but most of these studies have dealt with sharing, usually in the form of making an anonymous donation to someone in need, and, to a lesser extent, with rescuing, i.e., attempts to help another person in distress (Hoffman, 1976; Rushton, 1976). In one of the few experiments attempting to influence comforting behavior, Yarrow, Scott, and Waxler (1973) found that children who were exposed to both live and symbolic modeling by a nurturant adult caregiver were most inclined to help and to verbalize sympathy in real distress situations. Symbolic modeling, such as manipulation of characters in a diorama (a three-dimensional scene in which objects or figures are placed in front of a background picture), was highly effective in teaching children to response with sympathetic verbalizations or manipulation of the symbolic material, but had little effect on behavior toward real victims regardless of the nurturance or non-nurturance of the model. Staub, (1971a) demonstrated that both brief interaction with a nurturant adult who modeled helping and modeling alone increased kindergarten children's attempts to assist a supposedly distressed child, and that the combined effects of nurturance and modeling were greater than those of either condition separately. 
There is still a considerable amount of uncertainty as to why behavior changes as a result of having observed a model, though modeling has the obvious function of transmitting new response patterns, and the performance of either new or previously acquired behaviors may be facilitated by observing response consequences to the model (Bandura, 1965, 1971). Vicariously experienced reinforcement or punishment may alter the observer's anticipation of the probable outcome should he or she reproduce the model's behavior, which will in turn affect the probability of imitation (Mischel \& Mische1, 1976). It has also been suggested (Bryan \& London, 1970) that the model's behavior in an experiment gives child subjects information about what acts are permissible, indicates to the child what is expected of him or her, or if the child is inhibited in the experimental situation, reduces inhibitions restraining prosocial acts.

There is convincing evidence that the apparent status and power of a model relative to the observer affects the extent to which the modeled behavior is imitated, with the behavior of high-status or powerful models more likely to be reproduced than that of models who lack these characteristics (Bandura, 1971). To the extent that children perceive adults as having control over their actions or desired resources, one might expect them to imitate adult models more readily than child models. However, there is also evidence that similarity between model and observer fosters imitation (Rosekrans, 1967), which could lead to the opposite prediction. Consideration of Bryan and London's (1970) line of reasoning suggests that a peer model should convey more information regarding the permissibility and appropriateness of engaging in the modeled behavior. 


\section{Induction}

Bandura (1971) has noted that verbal instructions and descriptions of behavior may convey the essential features of a response or delineate its consequences, as live modeling does, and that verbal labeling of modeled responses may enhance the effects of observational learning. Hoffman (1970) also has pointed to the importance of verbal elaboration of the effects of behavior in socialization processes. The term "induction" has been used to describe techniques in which explanations or reasons for changing one's behavior are given, or processes which may activate conformity-inducing tendencies within the child (e.g., appeals to pride or concern for others). Hof fman considers "other-oriented" induction, which involves pointing out the harmful consequences of one's behavior toward others, calling attention to their needs or desires, or explaining the other person's motives, to be especially important in generating internalized control of behavior. Staub (1971b) investigated the effects of role-playing and induction on kindergarten children's subsequent helping and sharing behavior. He hypothesized that empathy would be engendered and the likelihood of prosocial responses increased if he not only pointed out the negative emotions experienced by others, but stressed the positive consequences for the victim when help is given. This prediction was not confirmed; compared with or combined with role-playing, induction did not affect helping or sharing with another child and decreased children's inclination to help an adult. Staub suggested that lack of prior experience with the experimenter and the fact that she had no further control over the child's behavior were in contrast to everyday 
practice, where both induction and parental control are ongoing processes. Indeed, Hoffman (1970) cites evidence that parental discipline of an inductive nature is associated with consideration for others and internalization or moral standards.

\section{SEX AND AGE DIFFERENCES}

In the studies mentioned above, significant but inconsistent sex differences have been found, though it has been suggested that where quantitative differences appear, girls tend to show more prosocial responses than do boys (Rushton, 1976). Hoffman (1977), reviewing sex differences in various investigations of empathy and "related behaviors," cited 16 studies of empathy as shared affect; females obtained higher scores in each. While many of these differences were slight, he held that the probability that alf differences would have been in one direction by chance was slight also. Sex differences in studies measuring recognition of affect (e.g., Borke, 1971; Feshbach \& Roe, 1968; Kurdek \& Rodgon, 1975), however, have not been found consistently, nor are they consistently obtained in measures of cognitive and spatial perspective taking. Hoffman (1977) suggested that females "may have a more highly developed affective base for prosocial behavior than do males" ( $p .720$ ), but noted that both innate factors and socialization practices may be implicated in sex differences in the expression of empathy and related behaviors.

\section{OVERVIEW OF THE PRESENT STUDY}

This study had several purposes. First, an attempt was made to promote comforting behavior in children. Specifically, the influence 
of a peer model, and of modeling followed by an inductive statement, on the performance of a sympathetic response was assessed. Unlike most previous studies, a child was used both as the sympathetic model and as a victim in need of comforting. One group of children saw a six yearold girl respond sympathetically to an adult's feigned injury. A second group saw the same injury and response, followed by an inductive statement designed to provide information regarding the consequences of the model's actions, i.e., reinforcement to the model and comfort to the victim. A third group observed only the adult's injury. All of the children were then given the opportunity to themselves respond sympathetically to an apparent injury to the child model. It was hypothesized that the children who were exposed to both a sympathetic model and verbal elaboration of the modeled behavior and its consequences would be more inclined to exhibit similar behavior than those whose training included modeling only, and that both groups would be superior in this respect to children who had received no training.

Another purpose involved the attempt to relate children's ability to recognize and understand the emotions of others and the capacity for sympathy to actual sympathetic behavior in the live distress situation. Accordingly, two measures of the children's ability to judge another person's affective state were obtained and related to their responses to the injured peer. One measure (an affective perspectivetaking task) was patterned after Kurdek and Rodgon's (1975) adaptation of Borke's (1971) material; the other, a measure of children's knowledge of appropriate strategies for intervening when another person is in distress, was developed by the author for the present study. It 
expected, on theoretical bases, that there would be a positive relationship between scores reflecting both the understanding of others' emotions (affective perspective-taking) and knowing how to offer and/or comfort (intervention strategies) and comforting behavior, and that performance on these measures would be better for older children than for younger ones. In view of the inconclusive results obtained previously with stimuli using incongruent facial and situational cues to others' emotions, no specific predictions were made regarding children's use of either source of information in making affective judgments. No sex differences on any measure were anticipated. 


\title{
CHAPTER II
}

\author{
METHOD
}

\section{SETTING}

This study was conducted at the Canterbury Learning Tree Day School, in Tigard, Oregon. The experimental setting consisted of a small room in which a one-way vision observation booth had been installed; furnishings included a child's folding table and chairs, a small trunk, and an assortment of objects provided to stimulate conversation.

\section{SUBJECTS}

Thirty-six boys and girls from the Canterbury School served as subjects. These children were from a predominantly white, middle-class population, with a large proportion of single-parent households. Written parental consent and willingness on the part of the child were prerequisites for participation.

\section{PROCEDURE}

Children were randomly assigned to one of three treatment conditions. The subject pool was divided at the median age into two groups, 33 to 51 months and 52 to 75 months of age. Both sexes and the two age groups were equally represented in each condition. Four subjects who became unavailable were each replaced by the same-sex child near- 
est in age.

Subjects were seen individually in three 20-minute sessions usually occurring within one week. On each occasion, the first experimenter accompanied the subject to and from the experimental playroom where, in the first and third sessions, the second experimenter and child confederate were waiting. The second session was conducted by the first experimenter alone. Although nurturance as such was not at issue in this study, every effort was made to provide a uniformly nurturant and naturalistic context at all times. Table I provides an overview of the three sessions and the measures obtained.

Session 1

Establishing rapport was the major concern in the first session. Each subject was introduced to the child confederate and the second experimenter and engaged in conversation. When the subject appeared to be at ease, a guessing game was initiated. To close the session, a snack was served and the child was escorted back to his or her classroom.

\section{Session 2}

For the second session, the subject was seated at the table facing the experimenter, who explained that she was interested in learning about people's feelings. Four white index cards, each displaying a drawing of a child's face expressing happiness, sadness, anger, or fear were placed on the table facing the child. The child was asked to identify these expressions, and incorrect responses were corrected. If any one or more of the four responses were incorrect, the cards were rearranged and the task was repeated until all of the expressions were 
TABLE I

OVERVIEW OF THE THREE SESSIONS AND MEASURES OBTAINED

Session I: Building Rapport

Activities : Conversation, guessing games, snack

Personnel : Two experimenters, child confederate, one or two observers

\section{Session II: Cognitive Measures}

Task 1: Affective perspective-taking

Measures Obtained: Social comprehension, empathic judgment, projective judgment, explanation of affect, awareness of discrepancy.

Task 2: Knowledge of intervention strategies

Measures obtained: Social comprehension, intervention strategies

Personnel: First experimenter only

Session III: Experimental Situation

Activities : Conversation, Lotto game; feigned injury, snack

Control Condition

Second experimenter, child confederate left room. First experimenter bumped her head. Second experimenter, child confederate returned, game was resumed.

\begin{tabular}{l} 
Modeling \\
Condition \\
\hline Second experimenter \\
left room. First ex- \\
perimenter bumped her \\
head; child confeder- \\
ate modeled a comfort- \\
ing response. Second \\
experimenter returned, \\
game was resumed.
\end{tabular}

Modeling Plus Induction Condition Second experimenter left room. First experimenter bumped her head, child confederate modeled a comforting response. Second experimenter returned, discussion of incident, inductive statemend followed. Game was resumed

Both experimenters left room to look for lost card. Child confederate slammed trunk lid, feigning injury to her hand.

Measures obtained: Subject's response to child confederate's injury. Subject's reporting of injury.

Personnel: Two experimenters, child confederate, two observers. 
identified in one trial. When this criterion had been met, a practice item was presented to familiarize the child with the format of the ensuing tasks. The cards were shuffled and placed in front of the subject before presentation of each item of both tasks: the cards themselves provided a non-verbal response mode (pointing) for specifying emotions, and the sequence in which they were placed determined the order in which the experimenter mentioned the emotions for each item. (Pictures of the four faces may be found in Appendix A.)

Task 1 consisted of eight stories used by Borke (1971) and adapted by Kurdek and Rodgon (1975), illustrated by black and white cartoonstyle drawings of children whose facial expressions indicated happiness, sadness, anger, or fear. Facial expressions were congruent with the story in four of the items; in the remaining four items, the child was pictured with an emotion considered inappropriate to the story situation. Expressions and stores were paired as in Kurdek and Rogdon's (1975) study: Happy-afraid, sad-happy, afraid-angry, and angrysad. However, in line with Borke's (1971) suggestion that the same situation may produce differing negative emotions in different people, sadness was included as an acceptable description of the emotion suggested by the story for the items contrasting happiness (facial cues) with fear (narrative cues), and fear (facial cues) with anger (narrative cues). Examples of a congruent item and an incongruent item are presented in Figure 1; the remaining Task 1 items are illustrated in Appendix A. For each item, subjects were asked to identify the emotion of the main character and explain its occurrence. Congruent and incongruent items were alternated; one of four permutations of the 
Congruent Item, GIFT

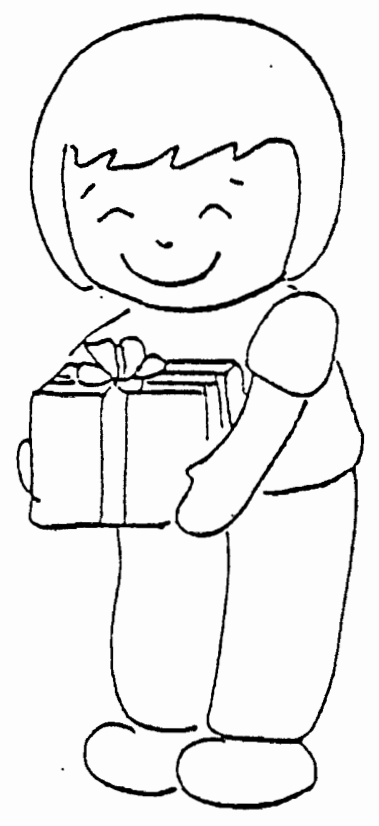

Here is a picture of John (Nancy). $\mathrm{He}$ (she is getting a new toy for a present.

How does John (Nancy) feel now?

(Does he (she) feel mad, or happy, or sad, or afraid?)

Why do you think he (she) feels

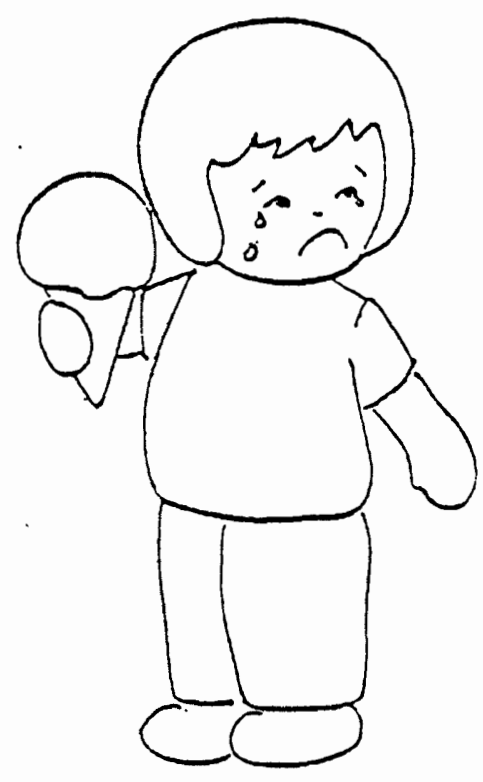

Incongruent Item, ICE CREAM

Here's John (Nancy) eating an ice cream cone. It's his (her) very most favorite kind of ice cream, the kind he (she) likes best.

How does John (Nancy) feel now?

(Does he (she) feel afraid, or sad, or mad, or happy?)

Why do you think John (Nancy) feels

Figure 1: Sample congruent and incongruent items from Task 1 . (Note: Original figures were five to seven inches in height.) 
eight items, each beginning with a congruent item, was randomly assigned to each subject.

In the six Task 2 items, brightly colored individual figures were arranged in a flannel board to present two characters in affectarousing situations, with one character observing while the other experienced some form of mild distress. For example, one item, shown in Figure 2, illustrated the "crying lady" scenario used by Yarrow and Waxler (1976), with a child identified as the subject playing with blocks and a woman crying while reading a book; the remaining items, with figures shown in typical arrangements, are illustrated in Appendix A. Two of the scenarios served as introductory and filler items. In the remaining four items, subjects were asked what they would do upon witnessing such events. If an appropriate course of action was offered, this was incorporated into the story by the experimenter; if not, the story continued with the observer making an offer of condolence to the victim, and the sad-faced characters of the original scene were replaced by happier-appearing versions. Subjects were asked to identify the characters' emotions at both the beginning and the end of each sequence. One of four permutations of the six items, with the filler items always occupying the first and fourth positions, was randomly assigned to each child.

For both tasks, each pictured child was shown with clothing and hair style appropriate for either sex. In Task 1, the main character was described as being the same sex as the subject. In Task 2 , the pictured child was identified either as the subject or as a friend or sibling the subject was invited to specify. All pictorial materials were designed by the author. 

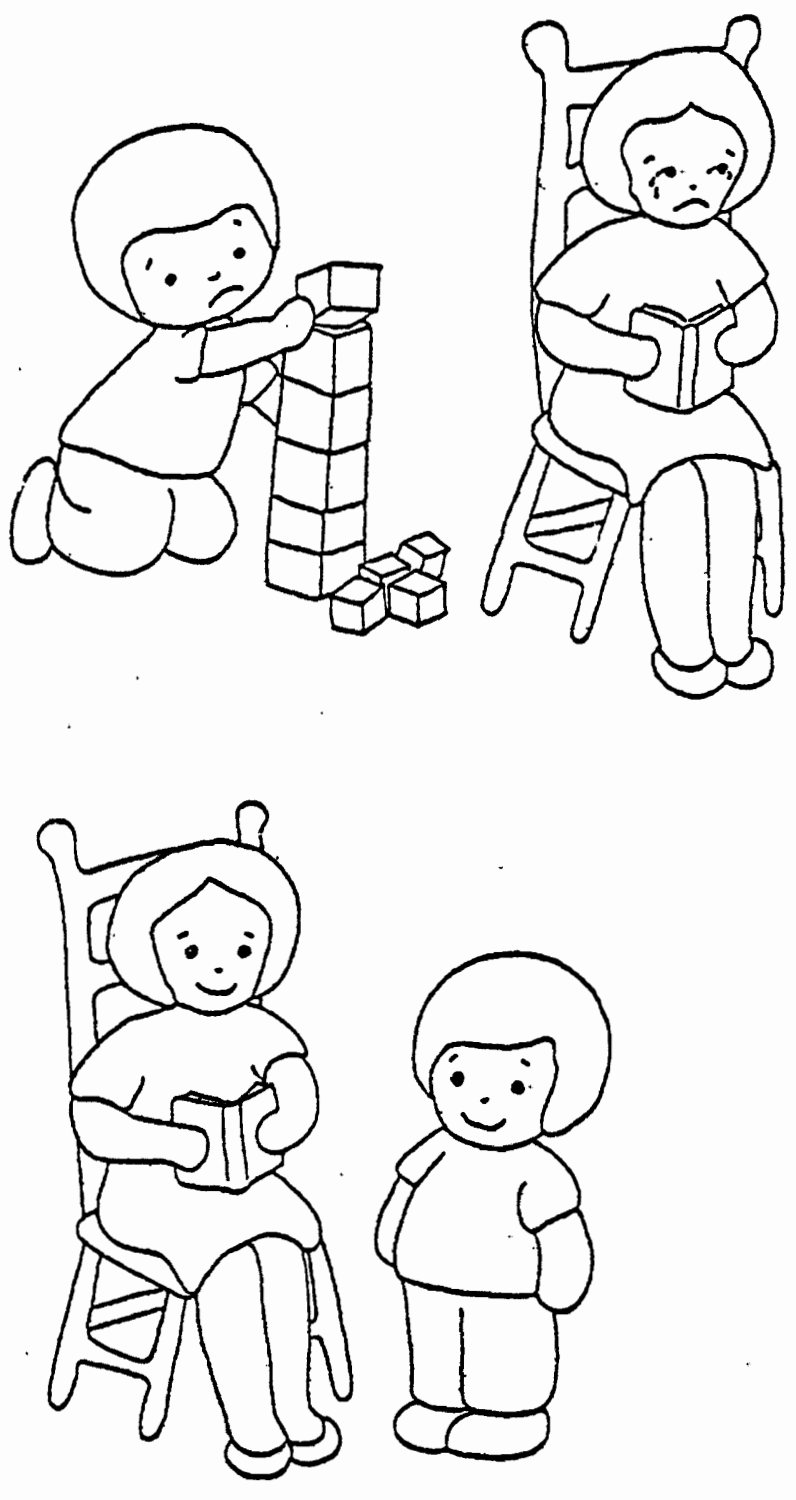

CRYING LADY

This is a story about you and a grown-up lady. See, you are sitting here playing with some blocks, and the lady is reading a book. Suddenly the lady starts to cry, and she cries and cries.

How do you feel?

How does the lady feel?

What would you do if you saw a grown-up lady cry like that?

Now, let's pretend that you go ask the lady what's the matter, and say something nice to her.

How does she feel then?

How do you feel?

Figure 2: Sample item from. Task 2. 
Session 3

In the third session, the two experimenters, the child confederate, and the subject played a game called "Lotto." The experimental manipulation occurred mid-way through the game. In the modeling condition $(N=12)$ the second experimenter left the room. While she was gone, the first experimenter pretended to bump her head on an overhanging shelf and the child confederate offered an appropriate sympathetic response. Leaving her chair and approaching the experimenter, she asked, "Are you all right?" and added, after a slight pause, "I hope it gets better soon." The experimenter replied that the child's response had indeed made her feel better, giving her a quick hug. When the second experimenter returned, she asked if anything had happened in her absence, giving the subject an opportunity to report the "injury." Unless he or she did so, the first experimenter said that she had bumped her head, but that it was "all right now," and the game was resumed. For the modeling plus induction group $(\mathrm{N}=12)$ the feigned injury and the modeled response were the same as in the modeling condition, but the second experimenter expanded the report into a discussion of the child confederate's sympathetic response, saying, "That was really nice of you to make $M$ ___ feel better." Turning to the subject, she added; "I'11 bet when people get hurt you like to make them feel better, too---I thought so." In the control condition $(\mathrm{N}=12)$, both the second experimenter and the child confederate left the room; subjects saw only the first experimenter's feigned injury.

For all subjects, upon finishing the Lotto game, it was discovered that a piece of the game was missing. The two experimenters left 
the playroom to search for the lost card, asking the child confederate to look for it in the room while they were gone. The child confederate opened the trunk, found that the piece was not there, and pretended to slam the trunk lid on her hand, verbalizing distress. The experimenters waited ten seconds, or until the subject had finished responding, before entering the room. Here, also, the subject was given an opportunity to report the incident and, to conclude, a snack was served.

Session 2 was conducted without observers. In sessions 1 and 3, verbal and nonverbal behaviors were recorded as a running narrative by one or two observers; with one exception, due to illness, two observers were present for session 3. All three sessions were tape recorded. Copies of the scripts for the trunk incident and the first experimenter's feigned injury may be found in Appendix B.

\section{SCORING}

Table II presents a list of all measures with the derivations and possible ranges of their scores.

Behavioral Measures

Responses to the child confederate's feigned injury were rated independently by three female judges for evidence of sympathy, using a 5-point scale. (This scale, with examples of responses at each level, is included in Appendix C.) Judges worked directly from session 3 tape recordings and copies of the two observers' narrative descriptions, edited in each case to eliminate reference to the subject's sex and to include only the time period when the two experimenters had left the room and the trunk incident occurred. A comforting behavior score 
TABLE II

LIST OF VARIABLES WITH DERIVATIONS AND POSSIBLE RANGES OF SCORES

Variable

Derivation of Score

$\underline{\text { Range }}$

Affective Perspective-Taking (Task 1)

Social

Comprehension

Explanation

of Affect

Empathic

Judgment

Projective

Judgment

Awareness of

Discrepancy
Proportion of subject's responses

to the four congruent items correctly specifying emotion

Mean of judges' ratings of subject's explanations of characters' emotions for the congruent items

Proportion of subject's responses to three incongruent items in which affect was specified in accord with the pictured facial expression

Proportion of subject's responses to three incongruent items in which affect was specified in accord with the narrative

Mean of judges' ratings of subjects' awareness of the discrepancy between facial and narrative cues in the four incongruent items

Knowledge of Intervention Strategies (Task 2)

Social

Comprehension

Intervention

Strategies
Proportion of subject's responses to the six Task 2 items correctly specifying emotion

Mean of judges' ratings for subject's knowledge of strategies for sympathetic intervention

\section{Sympathetic Behavior}

Comforting

Behavior

Mean of judges' ratings of sympathy evident in subject's responses to child confederate's injury

Reporting
Rating of subject's effort to inform experimenters of child confederate's injury

$$
\begin{aligned}
& .00-1.00 \\
& 1.0-4.0 \\
& .00-1.00 \\
& .00-1.00 \\
& 1.0-3.0
\end{aligned}
$$$$
.00-1.00
$$$$
1.0-5.0
$$

$1.0-5.0$

$0 \div 2$

Personal Characteristics of Subjects

Sex

Sex of subject ( $1=$ female, 2 = male $)$

$1-2$ 


\section{TABLE II (Cont'd.)}

Variable

Age

Age Group
Derivation of Score

Subject's age in months

01der and younger children ( $1=33-51$

months; $2=52-75$ months)
Range

$33-75$

$1-2$

for each child was computed by averaging the three judges' ratings. Children who spontaneously informed the returning adults of the trunk mishap received a reporting score of 2 ; reports elicited by the experimenter's question received a score of 1 .

\section{Cognitive Measures}

Task 1 congruent items were scored for social comprehension ( 1,0 ; 1 point for correct identification of the emotion depicted) and for explanation of affect (subject's ability to explain the emotion specified, rated on a scale of 1 to 4). The incongruent items were scored $(1,0)$ for empathic judgment and projective judgment separately. When scored for empathic judgment, responses in which the emotion specified by the subject matched the pictured facial expression were considered correct; scored for projective judgment, correct responses were those in which the emotion was specified on the basis of the situational (narrative) cues. In addition, the incongruent items were rated for the subject's awareness of discrepancy (ability to detect and reconcile the conflicting facial and narrative cues, on a scale of 1 to 3). Explanation of affect and awareness of discrepancy were rated independently by two female judges, with differences resolved by consensus; scoring criteria, with examples of responses at each level, may be found in Appendix $C$. 
The six Task 2 items were scored for social comprehension $(1,0$, for identification of each of the two characters' emotion at the beginning of each episode and again after the proposed intervention; scores for each item were computed as the proportion of the four emotional expressions identified correctly). For the four items in which subjects were asked what they themselves would do in such situations, responses were rated for knowledge of intervention strategies on a 5-point scale closely paralleling that used for rating sympathetic behaviors. Scoring criteria and examples of responses are included in Appendix C. .

\section{RELIABILITY}

Agreement among the three judges' ratings of comforting behavior was assessed by computing an intra-class correlation coefficient (Winer, 1971); reliability of a single judge was estimated at .94 , and reliability of the mean for the three judges was .98. Observer reliability for this measure was not an issue, since judges used both observers' narrative descriptions. Reliability of the two judges' ratings of explanation of affect, awareness of discrepancy, and knowledge of intervention strategies, as indicated by per cent agreement (agreements/ agreements + disagreements) was $95 \%, 92 \%$, and $95 \%$, respectively.

\section{DATA" ANALYSIS}

\section{Behavioral Measures}

Comforting behavior scores were subjected to a $3 \times 2 \times 2$ factorial analysis of variance (treatment $\mathrm{x}$ sex $\mathrm{x}$ age), with $\mathrm{N}=3$ children in 
each of the 12 cells. A $3 \times 2 \times 2$ factorial analysis of variance (treatment $\mathrm{x} \operatorname{sex} \mathrm{x}$ age) was also conducted on the scores for reporting the child confederate's injury, using unweighted means because of unequal cell frequencies (due to experimenter error, one child's score was not available).

\section{Item Analyses}

Pearson product-moment correlation coefficients were computed for items that were to be combined in forming each Task 1 and Task 2 composite measure; coefficient alpha (Nunnally, 1978) was used to estimate internal consistency reliability for each measure. In order to examine item differences by sex and age levels, $2 \times 2 \times \mathrm{N}$ analyses of variance (sex $\mathrm{x}$ age $\mathrm{x}$ items) with repeated measures on items were computed, followed where appropriate by post hoc comparisons among item means (differences in item means were presumed to reflect differences in item difficulty).

\section{Relationships Among Measures}

Correlational tests (Pearson $\underline{r}$ ) were used to investigate relationships among measures for the group as a whole and for boys and girls separately. Partial correlations, controlling for age, were obtained for all pairs of the following Task 1 and Task 2 variables: Social comprehension (for both tasks), explanation of affect, awareness of discrepancy, and knowledge of intervention strategies. 
CHAPTER III

RESULTS

Results for the behavioral measures will be presented first, followed by results for Task 1 and Task 2. Intercorrelations among all measures will then be presented. Mean scores and standard deviations for all variables (the two behavioral measures, the two social comprehension measures, explanation of affect, empathic judgment, projective judgment, awareness of discrepancy, intervention strateiges, and age are listed in Table III.

\section{BEHAVIORAL MEASURES}

The results of the $3 \times 2 \times 2$ analyses of variance (treatment $\mathrm{x}$ sex $\mathrm{x}$ age) for the children's comforting behavior and for reporting score's are presented in Appendix D. No significant effects due to treatment or to interactions involving treatment were obtained for either measure; consequently, the groups were combined and both the comforting behavior ratings and reporting scores were included in the later correlational investigation of relationships among task components. No significant age or sex differences were found for sympathetic behavior. Older children's scores for reporting the injury were higher than those for younger children $(\underline{F}(1,23)=4.92, p<.05)$. Since the sex $\mathbf{x}$ age interaction for the reporting scores approached significance, $(\mathrm{F}(1,23)=3.31, \mathrm{p}=.08)$, directional $\mathrm{t}$ tests were used to assess the 
된

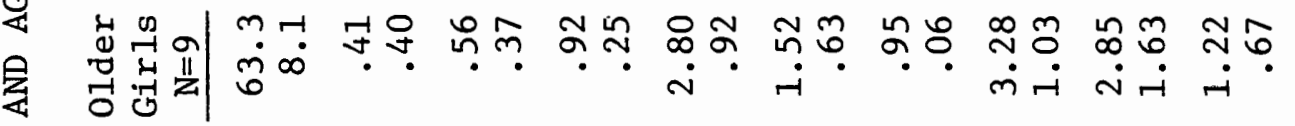

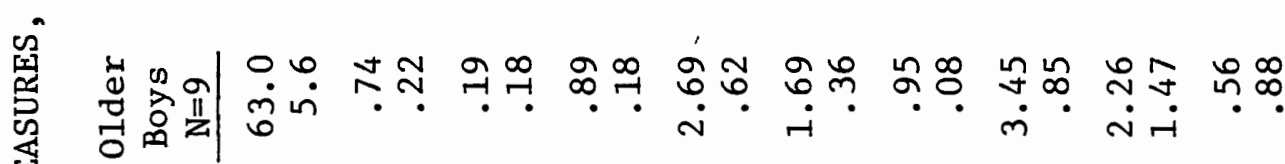

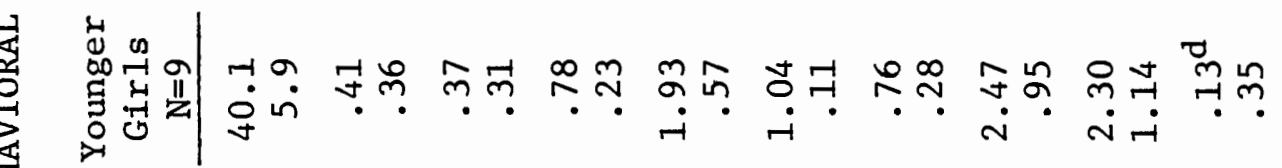
$\infty$

是

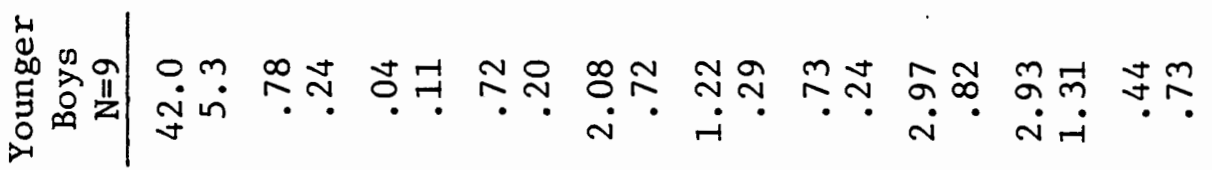
$\prod_{-1}^{-1}$

$\sim$

急

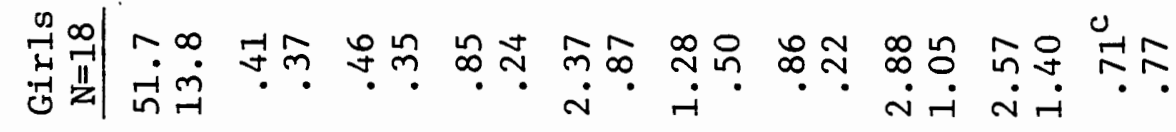

选

คั

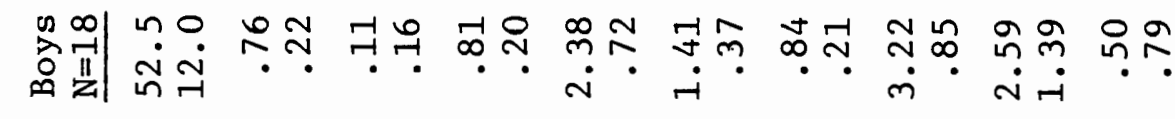
怘

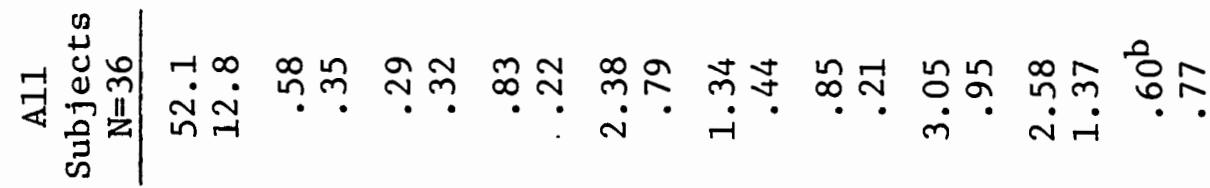

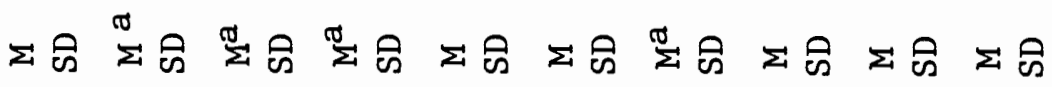
窟

会

运
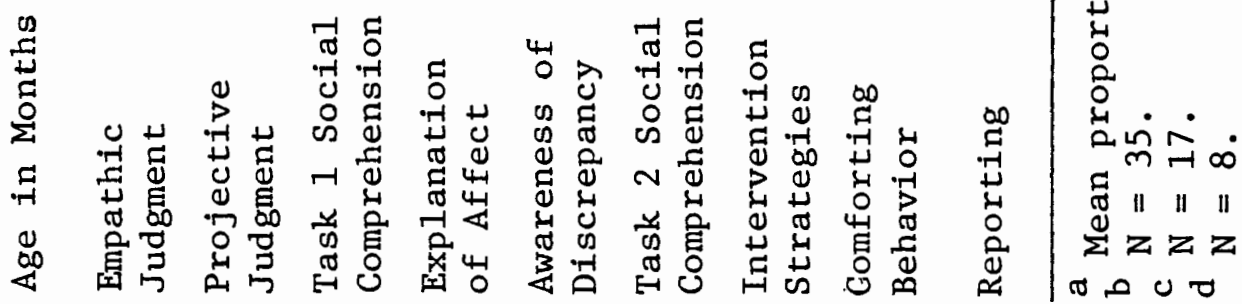
stability of the predicted age difference for each sex separately. No significant difference for older and younger boys was indicated, but older girls' scores were higher than those for younger girls (t (15) $=4.15, \mathrm{p}<.0005)$.

\section{ITEM ANALYSES}

Item intercorrelations, internal consistency reliability as estimated by coefficient alpha, and a summary of significant $\underline{F}$ values obtained in the repeated measures analyses of variance (sex $\mathrm{x}$ age $\mathrm{x}$ items) may be found in Appendix $\mathrm{E}$.

$\underline{\text { Task } 1}$

Item intercorrelations for social comprehension were computed on three of the four congruent items; since no child missed the item portraying happiness, correlation coefficients involving this item could not be obtained. Items were modestly intercorrelated $(\underline{r}=.15, p=.20$ to $\underline{r}=.29, \mathrm{p}<.05$; coefficient alpha $=.47)$. A Task 1 social comprehension score for each child was computed as the proportion of the congruent items identified correctly. The repeated measures analysis of variance indicated a significant difference among item means ( $\underline{F}$ $(3,96)=5.09, \mathrm{p}<.01)$. Newman-Keuls comparisons among item means revealed that the mean score for the item portraying happiness was significantly higher than mean scores for the three remaining items.

Children's explanation of affect ratings for the congruent items were moderately intercorrelated $(\underline{r}=.20, p=.12$ to $\underline{r}=.50, p<.001$; coefficient alpha $=.74)$, and each child's ratings across the four items were averaged to yield a composite score. Although the repeated 
measures analysis of variance indicated that there were significant differences among item means on explanation of affect $(\underline{F}(3,96)=$ $2.85, \mathrm{p}<.05)$. Newman-Keuls procedures revealed no significant comparisons among pairs of item means. However, $\underline{t}$ tests for simple main effects, using Dunn's procedure for keeping alpha constant for the set of four comparisons (Kirk, 1968) revealed that a significant age $\mathrm{x}$ items interaction $(\underline{F}(3,96)=2.88, \mathrm{p}<.05)$ was due to older children's higher scores for the items portraying sadness $\underline{t}(32)=3.62$, $\mathrm{p}<.01)$ and fear $(\underline{t}(32)=3.14, \mathrm{p}<.05)$.

Upon inspection of item intercorrelations for the three measures (empathic judgment, projective judgment, and awareness of discrepancy) derived from the incongruent picture stories, one of the items proved to be consistently unrelated to the three remaining incongruent items. This item, contrasting fear with anger or sadness, was excluded from composite scores for the three measures.

The empathic judgment scores for the three incongruent items retained were modestly intercorrelated $(\underline{r}=.14, p=.20$ to $\underline{r}=.40$, $\mathrm{p}<.01$; coefficient alpha $=.53$ ), as were those for projective judgment $(\underline{r}=.28, \mathrm{p}<.06$ to $\underline{\mathrm{r}}=.51, \mathrm{p}<.001$; coefficient alpha $=.67)$. Composite scores for each child for the two measures were computed as the proportion of items yielding empathic judgments and the proportion yielding projective judgments. Although no differences among item means were found for either empathic or projective judgments, the repeated measures analysis of variance indicated significant sex $\mathrm{x}$ items interactions for both measures $(\underline{F}(3,96)=2.82, p<.05$, and $\underline{F}(3,96)$ $=5.49, \mathrm{p}<.005$, respectively) $\underline{\mathrm{t}}$ tests, using Dunn's procedure, were 
used to investigate these interactions. Boys' empathic judgment scores were higher than girls' scores for the item contrasting hàppiness (facial cues) with fear or sadness (narrative cues) $(\underline{t}(32)=$ 2.96, $\mathrm{p}<.05)$. Girls' projective judgment scores were higher than boys' scores for this same item $(\underline{t}(32)=4.42, \mathrm{p}<.01)$, and for the item contrasting sadness (facial cues) and happiness (narrative cues) $(\underline{t}(32)=3.45, \mathrm{p}<.01)$.

The awareness of discrepancy ratings for the three retained incongruent items ranged from $\underline{r}=.27(\mathrm{p}=.06)$ to $\underline{\mathrm{r}}=.58(\mathrm{p}<.001)$; coefficient alpha $=.72$. Composite scores were obtained by averaging each child's ratings across the three items. A highly significant difference among item means $(\underline{F}(3,96)=7.84, \mathrm{p}<.001)$ was indicated by the repeated measures analysis of variance. As revealed by NewmanKeuls comparisons, mean scores for the two items contrasting positive and negative emotions (facial cues = happiness, narrative cues $=$ fear or sadness; facial cues = sadness, narrative cues $=$ happiness ) were significantly higher than those for the two items contrasting only negative emotions (facial cues = fear, narrative cues $=$ anger or sadness; facial $=$ cues $=$ anger, narrative cues $=$ sadness $)$.

\section{Task 2}

The six Task 2 social comprehension items proved to be strongly intercorrelated $(\underline{r}=.29 \mathrm{p}<.05$ to $\underline{r}=.91, \mathrm{p}<.001$; coefficient alpha $=.96)$, and each child's score for this measure was computed as the proportion of correct answers for the six items. The repeated measures analysis of variance indicated no significant differences among item means. However, a significant age $x$ items interaction 
emerged $(\underline{F}(5,160)=4.39, p<.005)$; $\underline{t}$ tests, using Dunn's procedure, revealed that mean scores for older children were higher for the four items comprising the intervention strategies measure, but not for the two filler items.

Intercorrelations for the four intervention strategies items were also high $(\underline{r}=.39, p<.01$ to $\underline{r}=.60, p<.001$; coefficient alpha $=.83)$. Each child's. ratings across the four items were averaged to obtain composite scores for this measure. A significant difference among item means was indicated by the repeated measures analysis of variance $(\underline{F}(3,96)=3.25, p<.05)$ : Newman-Keuls comparisons showed that only the highest and lowest item means differed significantly (child falling from wagon and child with broken leg, respectively).

Internal Consistency Reliability

For five of the seven Task 1 and Task 2 measures, explanation of affect, projective judgment, awareness of discrepancy, Task 2 social comprehension, and intervention strategies, internal consistency was considered satisfactory or better for research purposes (coefficient alpha $=.67$ to .96$)$. Alpha coefficients for the two remaining measures, Task 1 social comprehension and empathic judgment, were more marginal (.47 and .53, respectively), and results obtained with these measures should be interpreted cautiously.

SEX AND AGE DIFFERENCES

The repeated measures analyses of variance revealed significant main effects due to age for Task 1 social comprehension $(\underline{F}(1,32)=$ 
4.76, $\mathrm{p}<.05)$, for explanation of affect $(\mathrm{F}(1,31)=10.01, \mathrm{p}<.005)$, for awareness of discrepancy $(F(1,32)=13.0, p<.005)$, for Task 2 social comprehension $(F(1,32)=10.05, p<.005)$, and for intervention strategies $(F(1,32)=4.47, \mathrm{p}<.05)$. In each case, older children had higher mean scores than younger children. Older and younger children's mean scores for empathic judgment and projective judgment did not differ, however, but girls' mean scores for projective judgment were higher than those for boys $(F(1,32)=8.03, \mathrm{p}<.01)$.

\section{RELATIONSHIPS AMONG MEASURES}

Results of correlational tests assessing relationships among the Task 1 and Task 2 measures, the two behavioral measures, and age are shown in Table IV. While the large number of correlation coefficients computed suggests caution in interpreting these results, clear patterns emerged. For the group as a whole, social comprehension for both tasks, explanation of affect, awareness of discrepancy, and intervention strategies were highly intercorrelated $(\underline{\underline{x}}=.43, \mathrm{p}<.01$ to $\underline{r}=.69, \mathrm{p}<.001)$. Since these variables were also strongly related to age, partial correlation coefficients, controlling for age, were obtained. As may be seen in Table IV, these relationships generally remained quite strong $(\underline{r}=.19, \mathrm{p}<.14$ to $\underline{r}=.59, \mathrm{p}<.001)$. Children who made empathic judgments were somewhat more aware of the discrepancy $(\underline{r}=.33, \mathrm{p}<.05)$, but there were no further significant relationships between either empathic or projective judgments and any other measures. Projective judgments were more common among olden boys. 


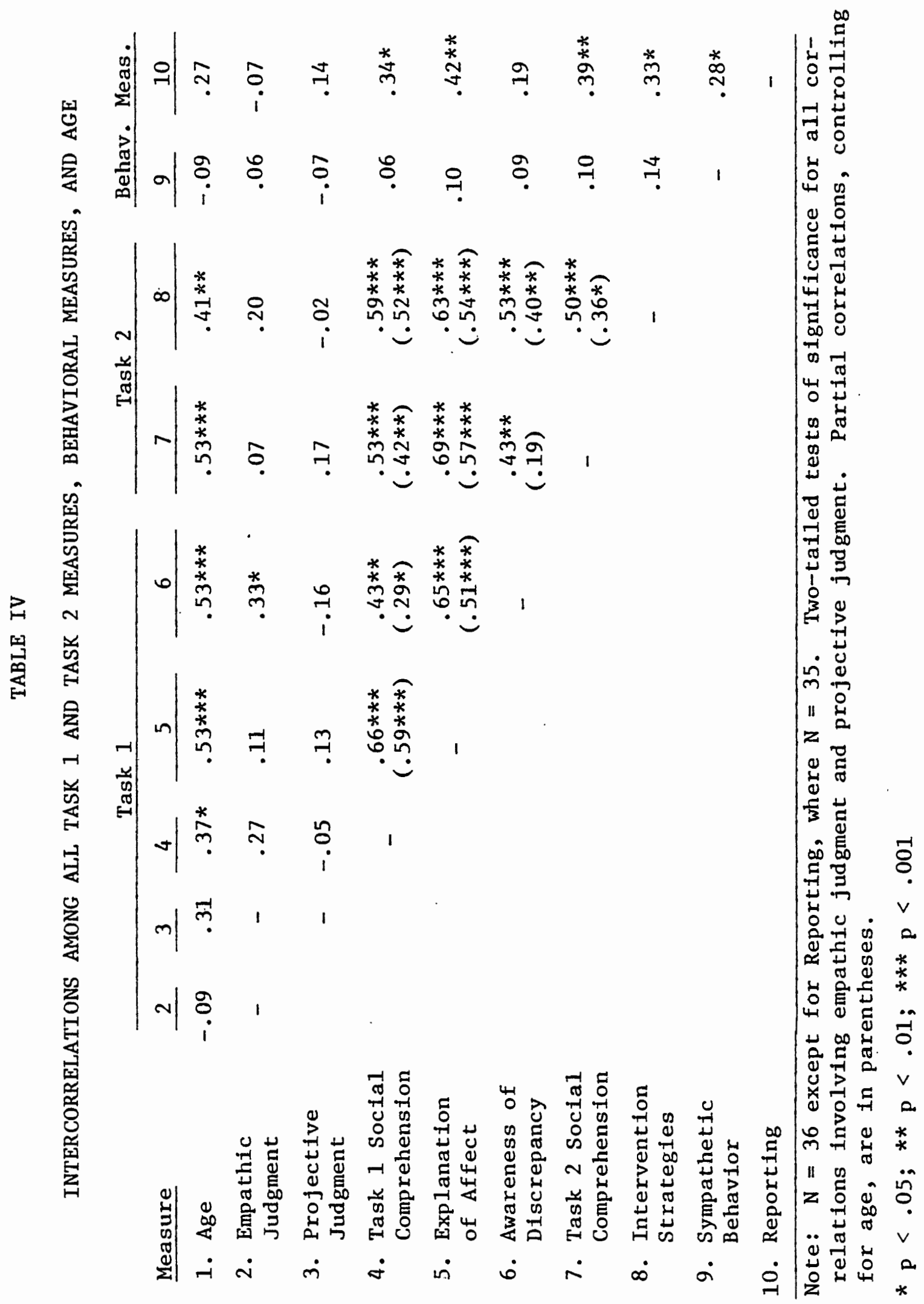


No Task 1 or Task 2 measure predicted comforting behavior. Although comforting behavior was significantly correlated with reporting the injury to the adults, the only other correlation involving comforting to approach significant suggested an inverse relationship with age for boys $(\underline{r}=-.44, p<.10$, two-tailed). Reporting was related to four of the five highly intercorrelated Task 1 and Task 2 measures (Task 1 and Task 2 social comprehension, $\underline{\underline{r}}=.34, \mathrm{p}<.05$ and $\underline{\underline{I}}=.39$, $\mathrm{p}<.01$; explanation of affect, $\underline{\mathrm{r}}=.42, \mathrm{p}<.01$; and intervention strategies, $\underline{r}=.39, \mathrm{p}<.001)$ and, for girls only, to age $(\underline{r}=.67$, $\mathrm{p}<.01)$ 
CHAPTER IV

\section{DISCUSSION}

In this study, very young children clearly demonstrated that they could distinguish between positive and negative emotions and, to a lesser extent, among the negative emotions of sadness, anger, and fear. Further, the ability to recognize a specific emotion within its appropriate situational context (social comprehension) was shown by children who were not yet three years old. As one would expect, these capabilities were more pronounced among the older children, as were the ability to offer appropriate explanations for another person's feelings (explanation of affect), to recognize instances in which affect is inappropriate to the situation in which it occurs (awareness of discrepancy), and to propose an appropriate course of action when another person is in distress (knowledge of intervention strategies). Even with age partialled out, these measures appear to have a great deal in common, and may be tapping a fairly broad category of social cognition. They are also related, no doubt, to overall cognitive development and verbal skills. But attempting to distinguish between empathic and projective judgments on the basis of a child's attention to facial expressions rather than situational cues does not fit into this picture, since the tendency to make empathic judgments was related to only one of the other measures, and projective judgments to none. Moreover, empathic judgments were not correlated with age for either sex, while projective 
judgments were actually more prevalent in older boys than in younger ones. Girls made a greater number of projective judgments than boys, but the sexes did not differ on any other measure.

Neither observing another child respond sympathetically to an adult's feigned injury by offering condolence, nor hearing an adult label and approve the modeled response, was effective in promoting sympathetic behavior when the child model herself appeared to be injured. Still, with the experimental groups combined, $28 \%$ of the children attempted to comfort the injured child (i.e., responded at point four or five on the behavioral rating scale), and $42 \%$ reported the mishap to the experimenters ( $17 \%$ did so spontaneously). Neither age nor sex influenced the probability of a comforting response. No part of the affective perspective-taking measure predicted comforting, nor were children who suggested an appropriate intervention strategy in response to a story character more likely to offer comfort in the live distress situation than those who did not. However, children who reported the injury were more likely to have offered comfort, and reporting was related to the ability to recognize and explain situationally consistent emotions and to propose a sympathetic response to the story character's distress.

The percentage of children who responded sympathetically, although lower than that obtained by Yarrow and Waxler (1976) under similarly structured observation, was considerably higher than the frequency of such behavior reported under field observation would suggest (cf. Yarrow \& Waxler, 1976; Eisenberg-Berg \& Lennon, 1980). We simply do not know, however, what proportion of sympathy-inviting mishaps in the real world actually elicit attempts to comfort the victim, and well-executed lab- 
oratory analogs of naturally-occurring events may provide a more accurate estimate of children's propensities for sympathy than can be obtained by merely tallying instances of comforting as they happen to occur. In this study, the child confederate's feigned injury was extremely realistic and consistent, and occurred in a very believable way; there was no evidence that any child saw the trunk incident as other than a natural happening. Further, demand characteristics of the experimental situation were minimized by having no adults present when the injury took place. Thus, it is plausible that naturally-occurring sympathetic behavior was sampled. Clearly, some very young children can and will attempt to comfort another child, but the antecedents of such behavior remain unclear.

Even though the experimental technique of modeling and induction used here did not influence the children's comforting behavior, it is highly improbable that the kinds of instructions and behavioral examples provided by socializing agents in everyday life, which this study attempted to simulate, are unrelated to children's inclinations to respond sympathetically. It is likely, however, that promoting sympathetic responses requires more prolonged exposure to training as part of the ongoing socialization process, and perhaps stronger methods than were used here. Indeed Zahn-Waxler, Radke-Yarrow, and King (1979) found that mothers' use of inductive statements when their children have caused another person's distress is related to the children's offering of aid and comfort even when they themselves have not caused the harm, but that mothers whose children were most inclined to be altruistic were forceful, emotional, and sometimes harsh in delivering the message. The 
modeling and inductive techniques which can be used ethically and practically in an experimental setting may simply be insufficient to the task of inducing the desired behavior.

One must conclude that individual differences in the children and their. backgrounds, to which the cognitive measures apparently were not sensitive, accounted for the variability in these children's sympathetic responding. However, differences in the extent to which demand characteristics affected responses to the cognitive and behavioral tasks may have lessened the chance of finding a positive relationship between the two kinds of measures, since the scores on the cognitive tasks were more likely to have been influenced by a desire to please the experimenter or to perform well. One child followed two responses in which she proposed helpful intervention strategies with, "I'm doin' good!" Such motivation may have been present in other children without finding overt expression, but was less likely in the live distress situation where, as noted previously, no adult was present. Indeed, comforting behavior toward the injured child may have been inhibited by fear on the part of the subject that opening the trunk was not permissible--one child who pulled seyeral things out of the trunk and played with them suddenly said, "Don't tell, okay? I don't like people who tell." It may be, also, that children whose verbal skills were sufficient for a response to the injured children confederate such as "Okay, it's okay, B ," lacked the ability to verbalize an explanation or sympathetic course of action in response to a direct question. In addition, it is likely that detecting whatever relationship between children's understanding of others' emotional expressions and needs might exist calls for more 
than one situational test of the child's behavior. As Green (1978) and Epstein (1979) have pointed out, demonstrating stable tendencies to act in particular ways usually requires the aggregation of behavioral measures across a number of situations. In all, the possibility that cognitive measures such as those used here might ultimately prove useful in predicting sympathetic behavior has not been ruled out.

of the cognitive tasks used in this study, four of the five strongly intercorrelated measures (explanation of affect, awareness of discrepancy, knowledge of intervention strategies, and the two measures of social comprehension) show that it is quite possible to develop items and construct scales with adequate internal consistency reliability, and all five indicate sufficient convergent validity to warrant their use for investigating issues involving social cognition in children. Whether or not they measure something other than general cognitive development and verbal skills remains to be determined (see Campbell \& Fiske, 1959, for a discussion of convergent and discriminant validation), but the stability of the correlations with age partialled out suggests a dimension of social sensitivity or competence which may vary somewhat independently of overall intellectual functioning. Perhaps a certain level of intelligence or achievement of a particular stage of cognitive development is necessary but not sufficient to explain performance on tasks such as these which, on the face of it, appear to assess children's understanding of other people's emotions and their situational referents, and knowledge of appropriate reactions to others' needs. However, the two remaining measures (empathic and projective judgment) 
do not appear to be related to this more general understanding of emotional events.

Whether perspective-taking is considered an aspect of cognitive structures, as within a traditional Piagetian frame of reference, or a way of gathering information, as.Turiel (1978) suggests, one would expect older children to be more successful than younger ones on any particular perspective-taking task. Thus, if the faculty for assessing other people's emotional states non-egocentrically is really indicated by predicting their feelings on the basis of expressive cues when these are at odds with the situation in which they occur, empathic judgment scores should have been higher for the older children. By the same reasoning, any evidence that projective responses increase among older children defies ready explanation; yet older boys in this study tended to give a greater number of projective judgments than did younger boys. These results are similar to those of Kurdek and Rodgon (1975), who found that projective responses increased steadily with advancing grade level for children of both sexes in their kindergarten through sixth grade sample. Together, the two studies suggest that projective responses become more prevalent as children progress through the age ranges of the Piagetian preoperational and concrete operational periods of cognitive development. This should not happen if the task correctly indexes a developmental trend away from egocentrism.

The overall sex difference in empathic and projective judgments, which replicated Kurdek and Rodgon's (1975) results, are not, as they also noted, easily interpreted; no clearly satisfactory reason for girls to make more projective judgments comes readily to mind. Discussing 
Kurdek and Rodgon's findings, Hoffman (1977) proposed that the particular situational cues used might have been more salient for girls, a plausible suggestion in light of the item analyses performed for this study. Since the sex difference did not hold for all items, it may thus be specific to certain situations and might in fact not represent a stable tendency for girls to respond more strongly to situational information.

The specification of a particular emotion when facial and situational cues are pitted against each other is not, in isolation, an adequate test of the child's ability to assume the emotional perspective of another person; the reasoning behind the choice must be taken into account. On the basis of empathic judgments alone, one cannot argue that perspective-taking has occurred. Some children who correctly named the pictured emotion did so without indicating any understanding of the situation. Their responses suggested that attention was focused solely or primarily on the facial cues, and thus provided evidence only for recognition of the expression. Other children took notice of both facial and situational cues. Fór example, some who recognized the sad expression on the face of the child with the ice cream cone asked, "Why is he sad?" or "Then how come he's crying?" These responses indicate that the feelings. of the child in the picture were unexpected, since items in which face and story were congruent provoked no such questions. This level of awareness of the conflicting cues suggests some ability to decenter (i.e., to consider more than one aspect of a situation at a time) and recognize a perspective diffexing from one's own. Still other children not only detected the discrepancy but offered explana- 
tions by which it could be reconciled. In response to the picture of a smiling child dreaming of being chased by a ferocious tiger, one girl said the child was happy "'cause she can run faster than the tiger!" This type of response was obtained from children as young as four and a half years, and shows that preschool children can, at least in some situations, recognize and offer a reasonable explanation for an emotional perspective that differs from their own. It is their awareness of and attempts to deal with discrepant information which allow the assertion that perspective-taking can be demonstrated by children of this age.

Together with the item analyses, children's awareness of the discrepancy between facial and situational cues helps to clarify a point or two with regard to the internal consistency of measures using incongruent items. As Borke (1971) pointed out, the same situation may, for example, produce anger in one person and sadness in another; thus, an item contrasting these two negative emotions may not seem incongruent at all. Here, the two items where expression and situation were both negative elicited significantly less awareness of the discrepancy than did the items contrasting a negative emotion with happiness, raising the possibility that for the child these supposedly incongruent items did not differ from those in which face and story together represented only one emotion. In this case, such incongruent items would be no more capable than congruent items of detecting a projective response. In addition, since for empathic judgment, projective judgment, and awareness of discrepancy one item was unrelated to the other three, and since intercorrelations of the three remaining items were somewhat marginal 
for empathic judgment, it may well be that the emotions themselves vary in salience for different children or across different situations. Such sources of variability across items would adversely affect item intercorrelations, and call into question the use of composite scores for such measures without reporting internal consistency reliability--a practice which is, unfortunately, not uncommon (e.g., Kurdek \& Rodgon, 1975; Urberg \& Docherty, 1976; Burns \& Brainerd, 1979).

In addition to the question of age-relatedness in empathic and projective judgments, empathic judgment scores should, logically, have been related to the other cognitive measures if they do indeed represent the more cognitively mature response. Yet except for awareness of the discrepancy between facial and situational cues, this was not the case. While it is perhaps not surprising that the tendency to make empathic judgments was correlated with awareness of the discrepancy, this relationship cannot be interpreted confidently. Examination of the children's. responses suggests that the discrepant facial expression could more readily be reconciled to a correctly specified facial expression than the other way around. For example, a six year-old who claimed that the crying child with an ice cream cone was happy said, "I wonder why she's crying. . . because if it's her favorite kind she'd probably be happy." In contrast, another six year-old thought the same character was sad "Because she might be eating it too fast and then she gets a headache." Since making empathic judgments was not related to higher-level responses to the other cognitive measures, it is not clear whether this one significant correlation represents a real relationship or a lack of independence between the two measures. An adequate recon- 
ciliation of the discrepant cues may virtually entail specifying the facial expression as the emotion felt.

Even if the methodological questions raised here were to be resolved, the use of facial expressions rather than situational information as the standard for non-egocentric judgment poses conceptual problems. Piaget has asserted that non-egocentric assessment of another's point of view requires. the construction of alternative perspectives by inference rather than by direct perception (Piaget \& Inhelder, 1948/ 1956; 1962). Thus, the incongruent items paradigm seems to entail a contradiction, since making an inference about other people's feelings on any basis other than situational information requires direct perception of their expressive cues. Further, as noted previously, a situationally based judgment is not necessarily egocentric, even though the perspective of a particular person has not been assumed. A judgment of how most people would feel in a given situation (i.e., normative judgment [Shantz, 1975]) would not constitute entrapment within one's own point of view but cannot be distinguished in the incongruent-items paradigm from the projection of one's own feelings onto another. This paradigm simply cannot be defended as an index of non-egocentric responding on the basis of the choice of emotions alone.

In a11, the results reported here are in accord with other research on egocentrism and/or perspective-taking, which to date does not support the notion that development of some one cognitive structure or unitary ability leads to being able to take another person's point of view (Kurdek \& Rodgon, 1975; Urberg \& Docherty, 1976; Rubin, 1978; Ford, 1979). While these findings are based upon the mobility to demonstrate consistent relationships among perspective-taking measures, it 
is sometimes not possible to classify even an individual response as unequivocally egocentric--or not. For example, while it may seem that the youngster who chooses a toy as a birthday gift for his or her mother presents a classic example of childlike egocentrism with regard to inferring preference (cf. Zahn-Waxler, Radke-Yarrow, \& Brady-Smith, 1977), such a task does not measure the ability to judge another person's emotion in a particular situation. In the present study, a boy who clearly recognized that the Task 2 crying lady was sad said he would "let her play with the blocks" which were in the possession of the child in the picture. The lady might not have cared much for blocks, though she could well have been pleased by the offer, but her preference is not the only issue. From the fact that the lady was crying, this child inferred that she was sad and apparently understood that something might be done to brighten her outlook. He correctly assessed her feelings, if not her taste. While it could be argued that this boy's suggestion was projective or normative in that he proposed an act which he or any other child might appreciate, where can any of us look for information on how to respond to another's plight except to our own experience or what we know of others? It would perhaps make more sense to view egocentrism as a persistent cognitive bias than as a particular aspect of cognitive structure that one either has or does not have, or to view perspective taking as an information gathering technique, as Turiel (1978) has recommended. As Flavell (1977) has pointed out, we are at risk for egocentric thinking all our lives, and the possibility that one's perception of others' needs and feelings is distorted inevitably persists. We need both a broader conceptualization 
of perspective-taking as a multidimensional skill and a clearer view of what it means to take another's point of view.

The problem of establishing an acceptable criterion for determining whether or when children are able to discern the emotional perspectives of others has not been resolved. Certainly more attention must be given to methodological issues; in particular, internal consistency reliability must be established before items are combined to form scales. Differences in stimulus materials need to be explored systematically if the homogeneous items needed for reliable scales are to be developed. More specifically, the use of the incongruent item paradigin as a measure of affective perspective-taking is of little value unless the task is'structured so that the choices themselves have clear implications (e.g., Gove \& Keating, 1979), or children's explanations of their judgments are probed, as in the awareness of discrepancy measure in this study. Despite the shortcomings of this paradigm as it is currently used, however, incongruent stimulus materials might be used productively to explore the relative contributions of expressive and situational information to children's perception and understanding of others' emotions.

In a more encouraging vein, the intervention strategies task designed for this study evinced no particular psychometric problems, and did indeed provide insight into children's knowledge of what to do when faced with another person's distress. It als o provided some interesting comparisons with comforting behavior in the live distress situation. For example, a number of children suggested actions which would help, rather than console, the picture-story victim ("I would go help--I would 
pick the wagon up for him."), and some indicated that they would report the event to an adult. Although the need for direct assistance was not evident when the child confederate appeared to be injured, several children spontaneously told the returning adults of the mishap. Such reporting may well be construed by the child as a way of helping, and was related to the knowledge of intervention strategies as well as to social comprehension, explanation of affect, and comforting behavior. It is interesting that in the measure of intervention strategies the three children under five years of age who said they would seek adult help offered to get or tell their own parents, while those five and over would contact the victim's parents ("If they told me where they live, I would go to their house!")'. Inquiries regarding the other person's condition ("Are you okay?" "I would just say, 'are you all right?"") were common to both conditions, as were statements of reassurance ("It's okay." "I would say, 'Hey! It's gonna be okay, man'."). Common to both measures also were warnings or admonitions ("You have to watch out!" "He pick those apples--he be careful, he be careful!") The stories involving injury frequently triggered associations with the child's own painful experiences ("I hurt my back. . . I show you my hurt." "I got a sore now."), a type of response not unusual even in adults. Such associations were not expressed in the live distress situation, although experience with pilot subjects had indicated that they could be expected.

The examples of children's ability to state appropriate intervention strategies show that some young children do indeed have such knowledge. In addition, they indicate the possibilities inherent in 
this measure for allowing children to demonstrate what understanding they have. Since information concerning children's knowledge and attitudes with respect to situations which invite offers of help or condolence is scarce and largely anecdotal, this format offers a promising avenue for fuxther exploration.

This study suggests that children begin to recognize and understand others' emotions at a very early age, whether or not they differentiate feelings from their contextual determinants (cf. Gove \& Keating, 1979). But throughout life situational information is bound to interact with the perception of emotional cues. Children may learn to rely on normative judgments, which would reduce the amount of information required to process each person/situation interaction, and, in addition, must eventually come to realize that people do not always express their emotions viridically. Further, observers and actors alike may have been taught to suppress the expression of their own feelings, and to refrain from commenting on the affective displays of others. And, of course, sooner or later a child learns to make inferences about the emotions of others who are absent, from descriptions of their plight alone. Although children as they get older do become increasingly able to infer the inner states of others (Flapan, 1968), it is most likely that they do not learn to downgrade the context of emotion so much as to integrate situational and expressive cues. Which source of information dominates the child's perception of emotion at any one time may vary with the relative strength of the two sets of cues, which emotion is involved, and the nature of the situation.

Finally, the relationship between assuming another person's emo- 
tional perspective, or knowing how to offer consolation, and behavior toward others is not simple or straightforward. There is no necessary connection between comprehension of another's feelings and treating that person well; such knowledge may not be acted on at all or may even be used to one's own advantage at another's expense. Thus, the investigation of cognitive influences on prosocial behavior calls for some concern for the motivation behind whatever uses to which knowledge and understanding are put. Further, one's own emotional responsiveness may color judgments about emotions perceived in others just as cognitive processes come into play when we interpret our own or others' affect. Zajonc (1980) has characterized affect and cognition as partially independent systems which can interact in many ways, varying somewhat independently as they affect the processing of information. Viewed in this light, we are really facing the effects of a very complicated set of interactions. While measures such as those used here must often deal with abilities and events more or less in isolation, we would do well to bear in mind that the interrelationship of cognition, emotion, and behavior is rich and complex, and to interpret the evidence we garner against the background of this intricate and fascinating interaction. 


\section{BIBLIOGRAPHY}

Bandura, A. Influence of models' reinforcement contingencies on the acquisition of imitative responses. Journal of Personality and Social Psychology, 1965, 1, 589-595.

Bandura, A. (Ed.) Psychological modeling. Chicago: Aldine-Atherton, 1971.

Barden, R. C., Zelko, F. A., Duncan, S. W., \& Masters, J. C. Children's consensual knowledge about the experiential determinants of emotion. Journal of Personality and Social Psychology, 1980, 39, 968-976.

Borke, H. Interpersonal perception in young children: Egocentrism or empathy? Developmental Psychology, 1971, 5, 263-269.

Bryan, J. A., \& London, P. Altruistic behavior by children. Psychological Bulletin, 1970, 73, 200-211.

Buckley, N., Siegel, L. S., \& Ness, S. Egocentrism, empathy, and altruistic behavior in young children. Developmental Psychology, $1979,15,329-330$.

Burns, N., \& Cavey, L. Age differences in empathic ability among children. Canadian Journal of Psychology, 1957, 11, 227-230.

Burns, S. M., \& Brainerd, C. J. Effects of constructive and dramatic play on perspective-taking in very young children. Developmental Psychology, 1979, 15, 512-521.

Campbe11, D. T., \& Fiske, D. W. Convergent and discriminant validation by the multitrait-multimethod matrix. Psychological Bulletin, 1959 , 56, 81-105.

Chandler, M. J. Social cognition: A selective review of current research. In W. F. Overton \& J. M. Gallagher (Eds.), Knowledge and development (Vo1. 1). New York: Plenum Press, 1977.

Chandler, M. J., \& Greenspan, S. Ersatz egocentrism: A reply to H. Borke. Developmental Psychology, 1972, 7, 104-106.

Eisenberg-Berg, N., \& Lennon, R. Altruism and the assessment of empathy in the preschool years. Child Development, 1980, 51, 552557. 
Epstein, S. The stability of behavior: I. On predicting most of the people much of the time. Journal of Personality and Social Psychology, 1979, 37, 1097-1126.

Feshbach, N. D. Empathy in children: Some theoretical and empirical considerations. The Counseling Psychologist, 1975, 5, 25-30.

Feshbach, N. D., \& Roe, K. Empathy in six- and seven-year-olds. Child Development, 1968, 39, 133-145.

Flapan, D. Children's understanding of social interaction. New York: Teachers College Press, 1968.

Flavel1, J. H. Cognitive development. Englewood Cliffs, N.J.: Prentice-Hall, 1977.

Ford, M. E. The construct validity of egocentrism. Psychological Bulletin, 1979, 86, 1169-1188.

Gove, F. L., \& Keating, D. P. Empathic role-taking precursors. Developmental Psychology, 1979, 15, 594-600.

Green, B. F. In defense of measurement. American Psychologist, 1978, 33, $664-670$.

Greenspan, S., Barenboim, C., \& Chandler, M. J. Empathy and pseudoempathy: The affective judgments of first- and third-graders. Journal of Genetic Psychology, 1976́, 11, 643-650.

Hoffman, M. L. Moral development. In P. H. Mussen (Ed.), Carmichael's manual of child psychology (3rd Ed., Vol. 2). New York: Wiley, 1970 .

Hoffman, M. L. Developmental synthesis of affect and cognition and its implication for altruistic motivation. Developmental Psychology, $1975,11,607-622$.

Hoffman, M. L. Empathy, role-taking, guilt, and the development of a1truistic motives. In T. Lickona (Ed.), Moral development and behavior: Theory, research, and social issues. New York: Holt, Rinehart \& Winston, 1976.

Hoffman, M. L. Sex differences in empathy and related behaviors. Psychological Bulletin, 1977, 84, 712-722.

Hoffman, M. L. Empathy, its development, and prosocial implications. In H. H. Howe \& C. B. Keasey (Eds.), Nebraska symposium on motivation: 1977 (Vo1. 25). Lincoln: University of Nebraska Press, 1978.

Hoffman, M. L. Is altruism part of human nature? Journal of Personality and Social Psychology, 1981, 40, 121-137. 
Iannotti, R. J. The many faces of empathy: An analysis of the definition and evaluation of empathy in children. Paper presented at the meeting of the Society for Research in Child Development, Denver, April 1975. (a)

Iannotti, R. J. The nature and measurement of empathy in children. The Counseling Psychologist, 1975, 5, 21-25.

Iannotti, R. J. Effect of role-taking experiences on role taking, empathy, altruism, and aggression. Developmental Psychology, $1978,14,119-124$.

Kirk, R. E. Experimental design: Procedures for the behavioral sciences. Belmont, Calif.: Brooks/Cole, 1968.

Krebs, D. K. Atlruism: An examination of the company and a review of the literature. Psychological Bulletin, 1970, 73, 258-302.

Kurdek, L. A. Perspective taking as the cognitive basis of children's moral development: A review of the literature. Merrill-Palmer Quarterly, 1978, 24, 3-28.

Kurdek, L. A. \& Rodgon, M. M. Perceptual, cognitive, and affective perspective-taking in kindergarten through sixth grade children. Developmental Psychology, 1975, 11, 643-650.

Mische1, W., \& Mischel, H. N. A cognitive social-learning approach to morality and self-regulation. In T. Lickona (Ed.), Moral development and behavior. New York: Holt, Rinehart \& Winston, 1976.

Murphy, L. B. Social behavior and child personality: An exploratory study of some roots of sympathy. New York:- Columbia University Press, 1937.

Mussen, P. H., \& Eisenberg-Berg, N. Roots of caring, sharing and helping. San Francisco: W. H. Freeman, 1977.

Nunnally, J. C. Psychometric theory (2nd Ed.). New York: McGrawHil1, 1978.

Piaget, J. The language and thought of the child (3rd Ed.). London: Routledge \& Kegan Paul, 1959. (Originally published, 1923)

Piaget, J., \& Inhelder, B. The child's conception of space. London: Routledge \& Kegan Paul, 1956. (Originally published, 1948)

Piaget, J., \& Inhelder, B. Le développement des quantités physiques chez l'enfant (2e éd.). Neuchâtel: Delachaux \& Niestlế, 1962.

Rosekrans, N. M., \& Hartup, W. W. Imitative influences of consistent and inconsistent response consequences to a model of aggressive behavior in children. Journal of Personality and Social Psychology, 1967, $\underline{7}, 429-434$. 
Rubin, K. H. Role taking in childhood: Some methodological considerations. Child Development, 1978, 49, 428-433.

Rushton, J. P. Socialization and the altruistic behavior of children. Psychological Bulletin, 1976, 83, 898-913.

Selman, R. L.. The growth of interpersonal understanding. New York: Academic Press, 1980.

Shantz, C. U. Empathy in relation to social cognitive development. The Counseling Psychologist, 1975, $\underline{5}, 18-21$.

Staub, E. A child in distress: The influence of nurturance and modeling on children's attempts to help. Developmental Psychology, $1971, \underline{5}, 124-132$. (a)

Staub, E. The use of role-playing and induction in children's learning of helping and sharing behavior. Child Development, 1971, 42, 805-815.

Staub, E. Positive social behavior and morality (Vol. 1). New York: Academic Press, 1978.

Strayer, J. A naturalistic study of empathic behaviors and their relation to affective states and perspective-taking skills in preschool children. Child Development, 1980, 51, 815-822.

Turiel, E. Social convention and morality: Two distinct conceptual and developmental systems. In C. B. Keasey (Ed.), Nebraska symposium on motivation. (Vo1. 25). Lincoln: University of $\mathrm{Ne}-$ braska Press, 1978.

Urberg, K. A., \& Docherty, E. M. Development of role-taking skills in young children. Developmental Psychology, 1976, 12, 198-203.

Webb, E. J., Campbe11, D. T., Schwartz, R. D., \& Sechrest, L. Unobtrusive measures: Nonreactive research in the social sciences. Chicago: Rand McNa11y, 1966.

Winer, B. J. Statistical principles in experimental design. New York: McGraw-Hill, 1971.

Wispé, L. (Ed.) Altruism, sympathy, and helping: Psychological and sociological principles. New York: Academic Press, 1978.

Yarrow, M. R., Scott, P. M., \& Waxler, C. Z. Learning concern for others. Developmental Psychology, 1973, $\underline{8}, 240-261$.

Yarrow, M. R., \& Waxler, C. Z. Dimensions and correlates of prosocial behavior in young children. Child Development, 1976, 47, 118125 . 
Zahn-Waxler, C., Radke-Yarrow, M., \& Brady-Smith, J. Perspective-taking and prosocial behavior. Developmental Psychology, 1977, 13, 87-88.

Zahn-Waxler, C., Radke-Yarrow, M., \& King, R. A. Child rearing and children's prosocial initiations toward victims of distress. Child Development, 1979, 50, 319-330.

Zajonc, R. B. Feeling and thinking: Preferences need no inferences. American Psychologist, $1980,35,151-175$. 
APPENDIX A

STIMULUS MATERIALS 
RESPONSE FACES

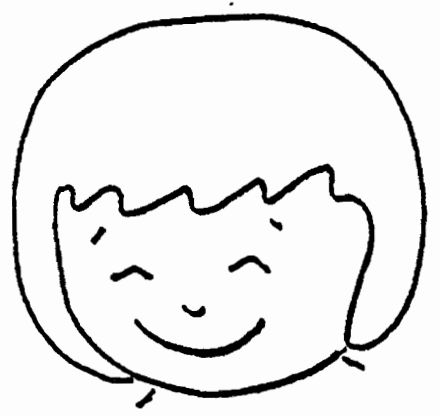

Happiness

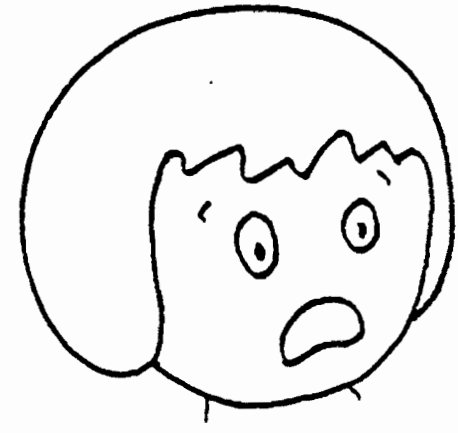

Fear

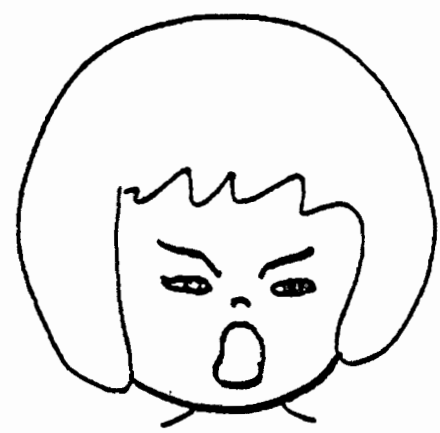

Anger

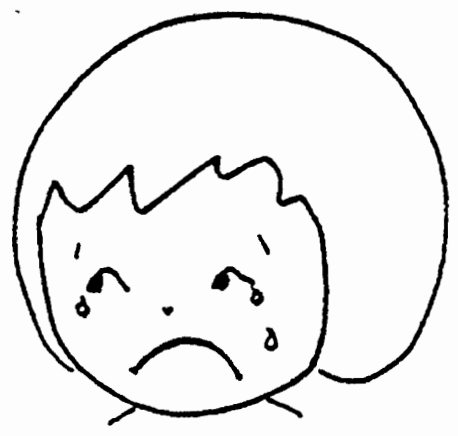

Sadness 
TASK I ITFMS

\section{Congruent Items}
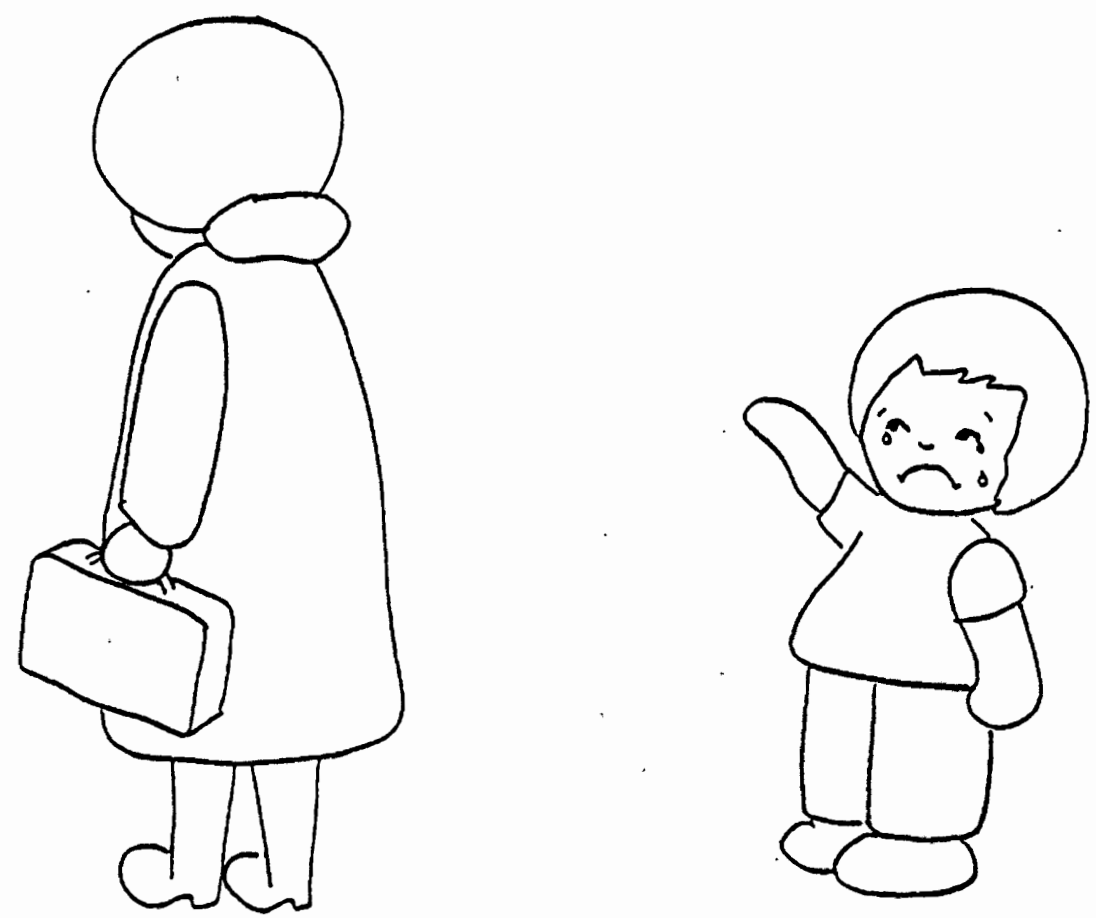

GOOD-BYE

I think this lady is John's (Nancy's) grandma. John (Nancy) likes his (her) grandma a lot, but now grandma has to go away and she won't be back for a long time.

How does John (Nancy) feel when his (her) grandma goes away?

(Does he (she) feel afraid or happy or sad or mad?)

Why does he (she) feel 


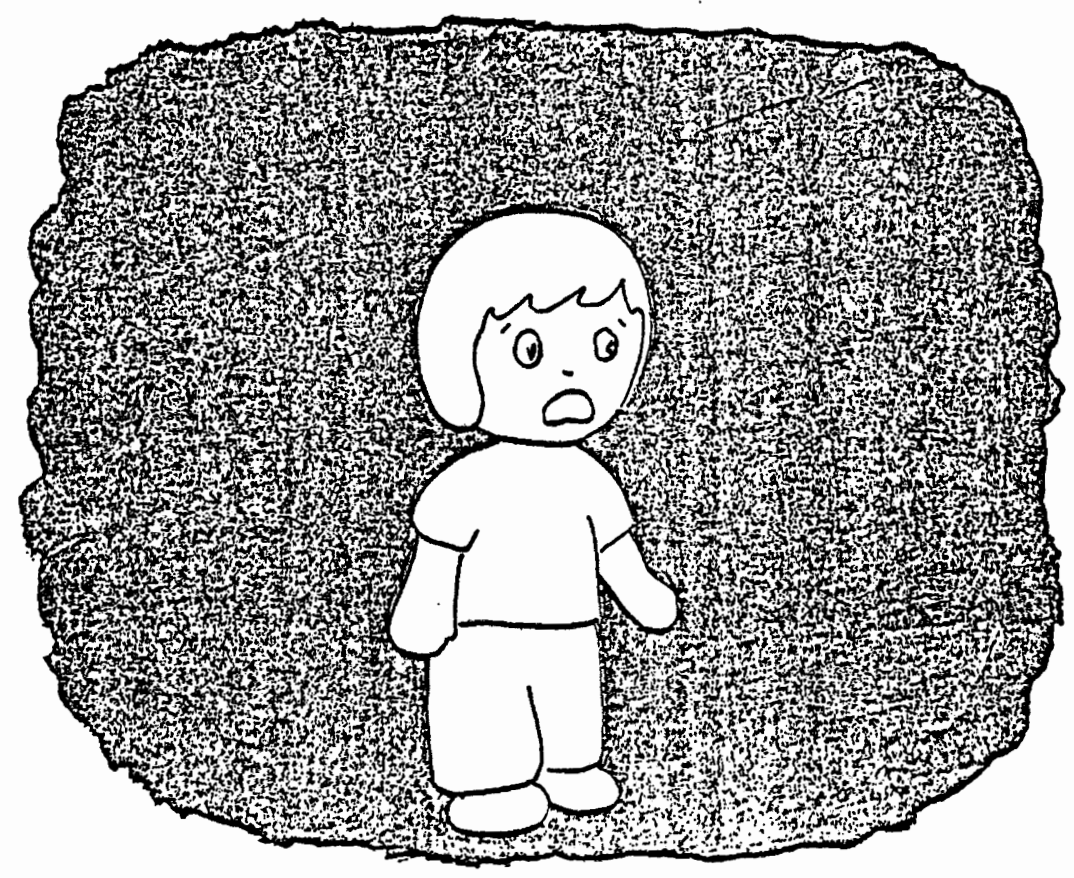

DARK

Look at this picture of John (Nancy). It's nighttime, and he (she) is all by himself (herself) in the dark. It's really dark!

How does John (Nancy) feel?

(Does he (she) feel happy or sad or afraid or mad?)

Why does John (Nancy) Feel $?$

(Continued) 


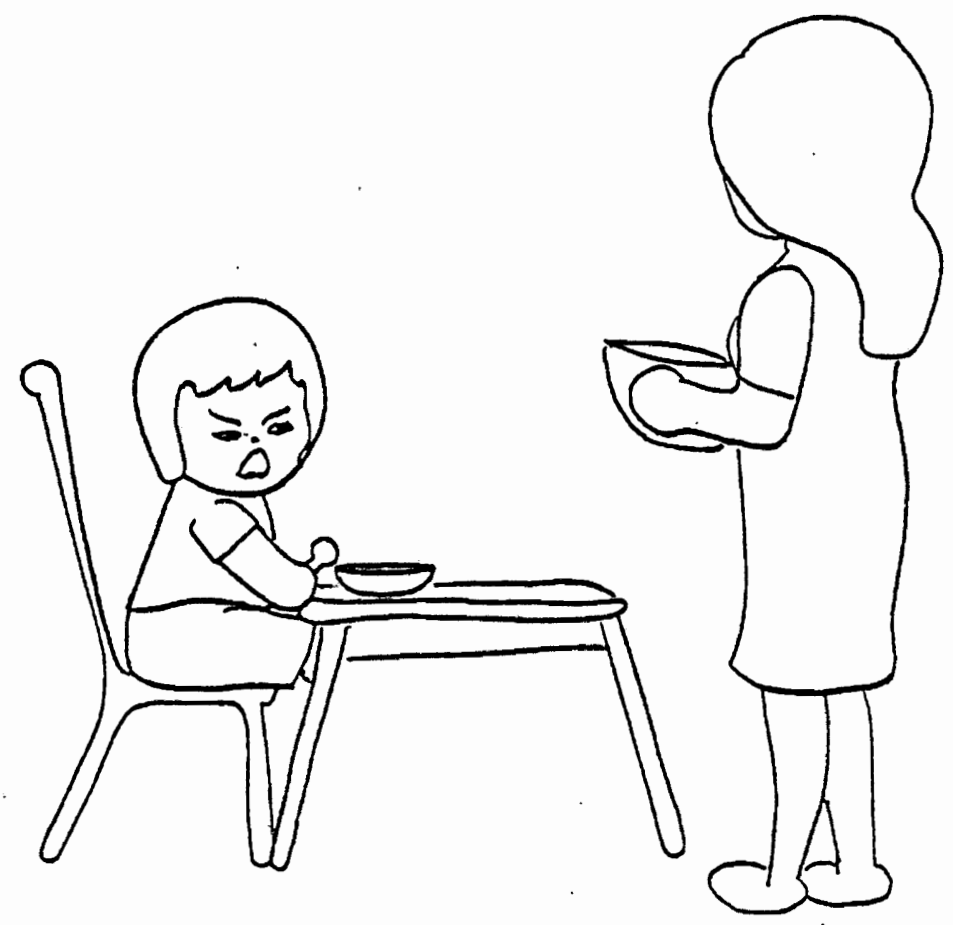

FOOD

Here is John (Nancy) eating breakfast. He (she) doesn't like what's in his (her) dish at all, but his (her) mother says he (she) has to eat it all up anyway.

How does John (Nancy) feel now?

(Does he (she) feel sad or afraid or happy or mad?)

Why do you think he (she) feels

(Continued) 


\section{Incongruent Items}

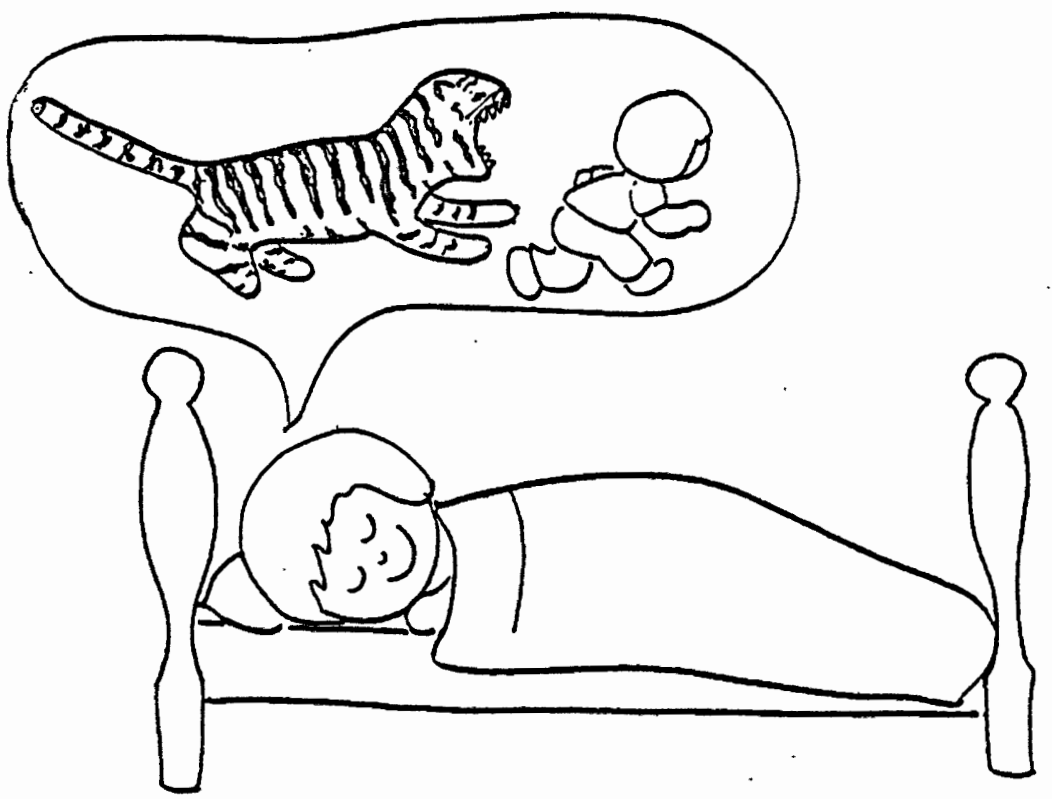

TIGER

Look at John (Nancy) in this picture. See, he (she) is asleep, and he (she) is dreaming that a big, mean tiger is chasing him (her).

How does John (Nancy) feel now?

(Does he (she) feel happy, or mad, or afraid, or sad?)

Why does John (Nancy) feel - 

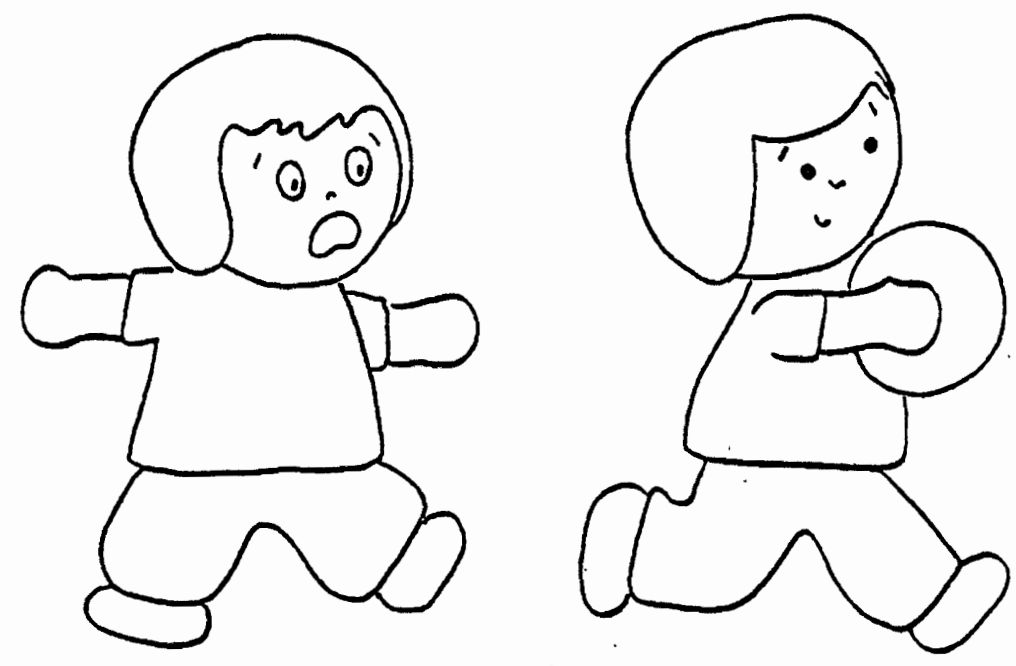

BALL

- John (Nancy) and his (her) friend were playing with his (her) new red ball. They were having a lot of fun, but then John's (Nancy's) brother. (sister) grabbed the ball and ran away with it.

How does John (Nancy) feel then?

(Does he (she) feel sad, or afraid, or mad, or happy?)

Why do you think John (Nancy) feels $?$ 


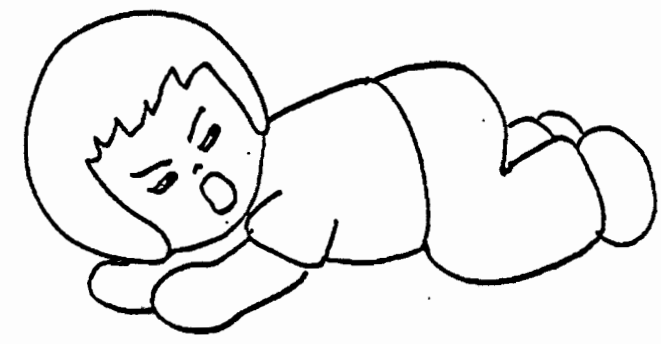

FALI

Oh, look! John (Nancy) fell down. He (she) was running really fast, and he (she) fell down and hurt himself (herself).

How does John (Nancy) feel?

(Does he (she) feel happy, or mad, or sad, or afraid?)

Why does John (Nancy) feel 
TASK 2 ITEMS
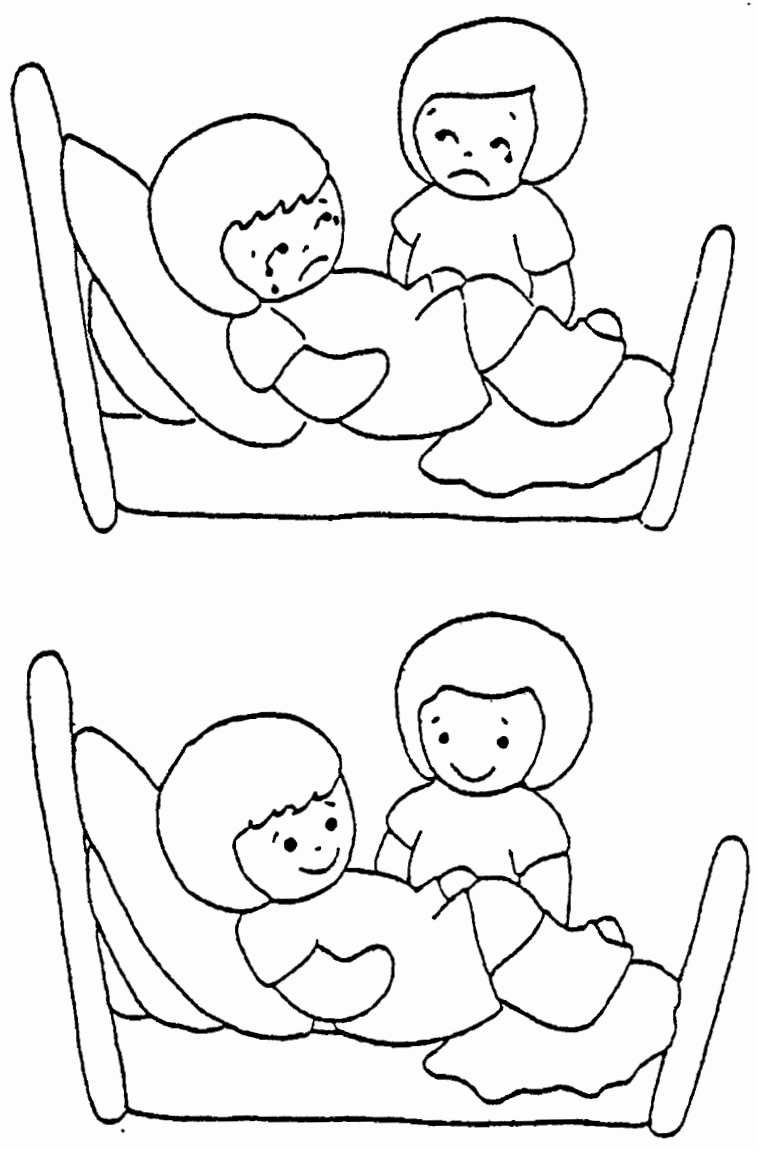

BROKEN LEG

Here you are and here's your friend was riding his

(her) bicycle one day and he (she) fell off and broke his (her) leg. It hurts a lot, and now can't go outside and play. You want to come out and play with you.

How does feel?

How do you feel?

What would you do if you went to your friend's house and he (she) had a broken leg and couldn't play?

Then you say, "Don't feel bad. I'Il stay for a while and we can play in here. Pretty soon you will feel better."

How does __ feel then?

How do you feel?

(Continued) 

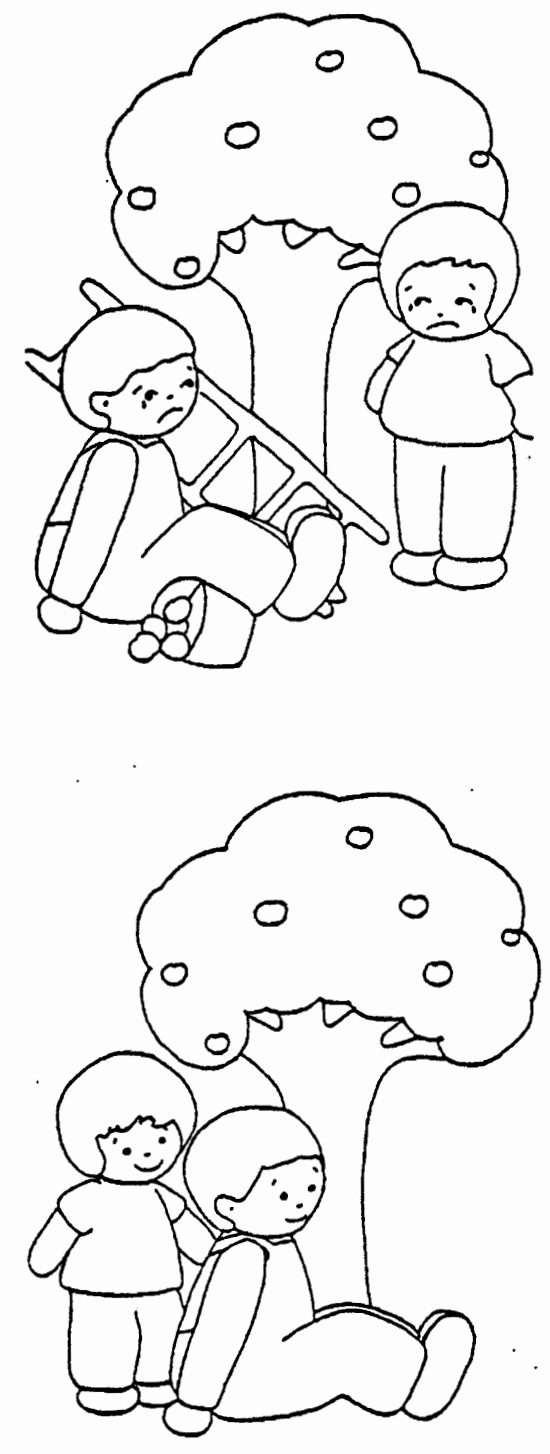

\section{APPLE TREE}

This is a story about a man and a boy (girl) who went out to pick some apples. They had a ladder, and a bucket to put the apples in, but the ladder slipped and the man fell down and hurt his leg.

How does the man feel?

How does the boy (girl) feel?

What would the boy (girl) do if he (she) saw someone fall like that?

The boy(girl) goes over to the man and asks if he is all right, and he (she) says, "I hope it doesn't hurt very much."

How does the man feel then?

How does the boy (girl) feel? 
WAGON

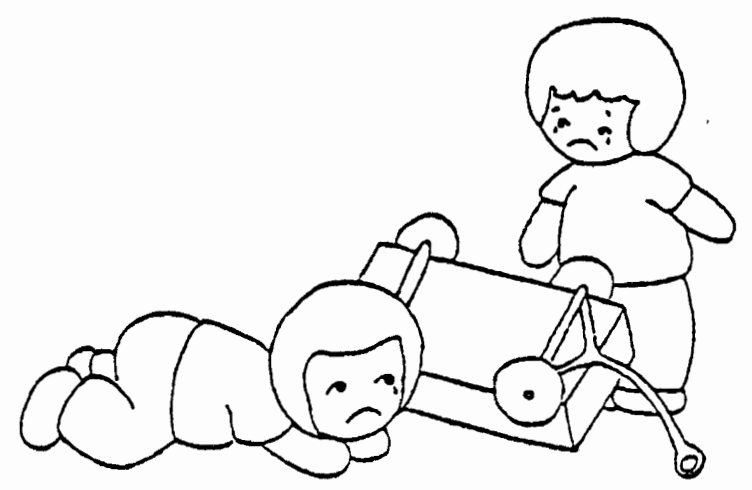

Look, here is a picture of you. You were zooming down the hill in a wagon, but the wagon tipped over and you fell out and skinned your knee. It really hurts! Your friend is standing there and sees you get hurt.

How do you feel if this happens to you?

How does your friend feel?

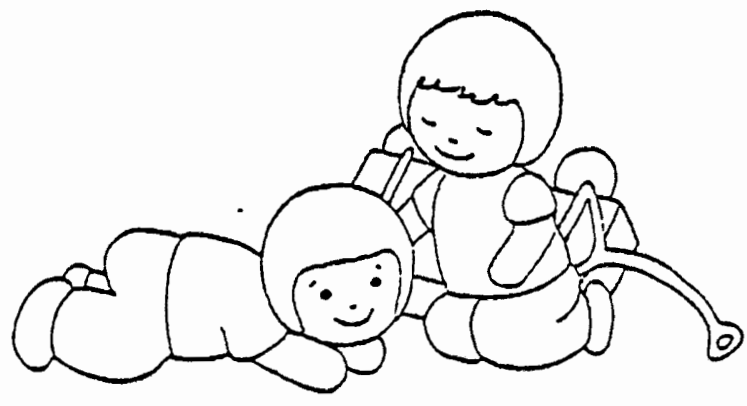

What would you do if you saw someone get hurt like that?

Then says, "Does it hurt? It will feel better pretty soon."

How do you feel then?

How does your friend feel?

(Continued) 


\section{PICNIC}

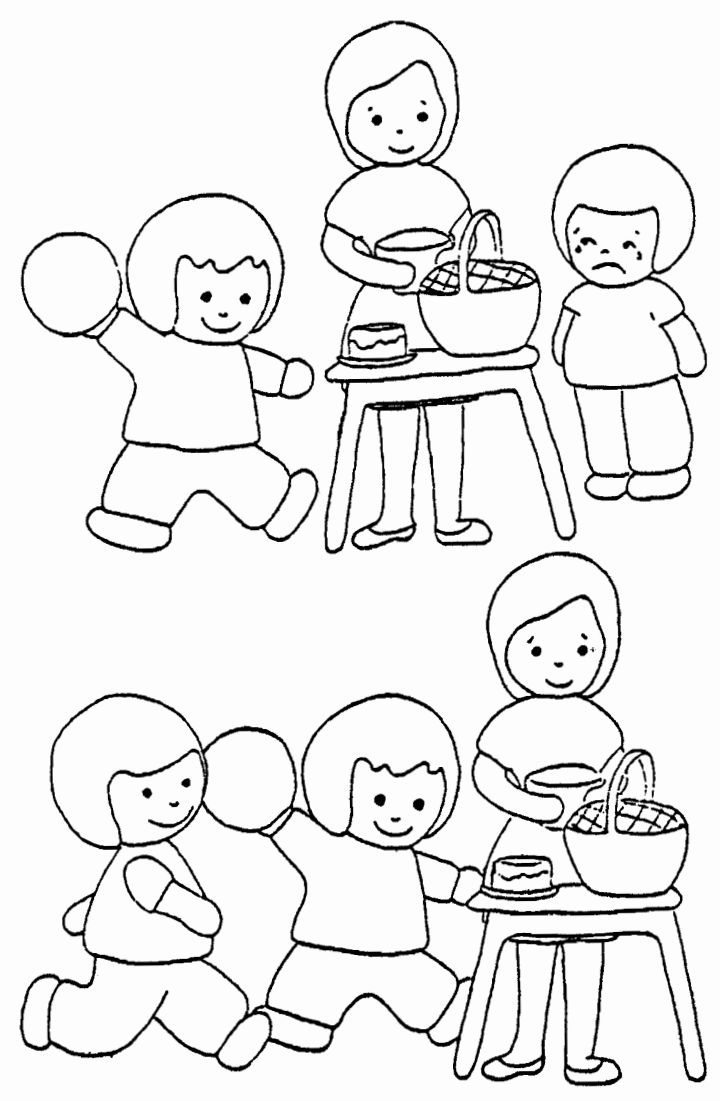

Let's pretend this is a picture of you. You are at your friend's house, and his (her) mom is getting reach for a picnic, putting good things to eat into a basket. is getting some toys to play with. You are wishing you could go too, instead of staying home alone.

How do you feel?

How does your friend feel?

Then your friend's mom says, "Why don't you go ask your mother if you can come too?" So you run home and ask, and your mom says you may.

How do you feel then?

How does your friend feel?

(Continued) 
BEACH
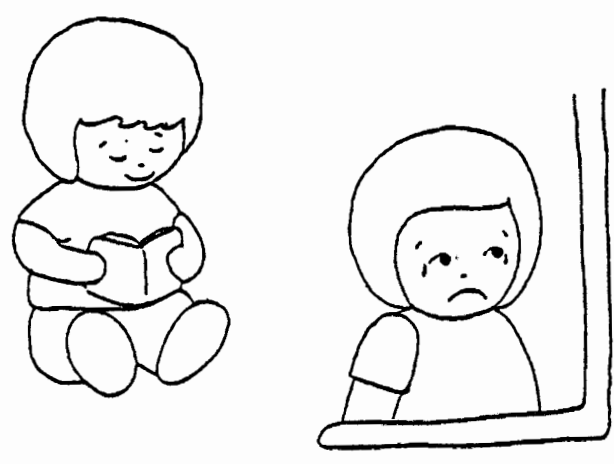

Here you are at the beach. But you and your brother (sister) have to stay in the cabin because it's raining. Your brother (sister) has a book to look at, but you don't have anything to play with.

How do you feel?

How does your brother (sister) feel?

Then the sun comes out, and it

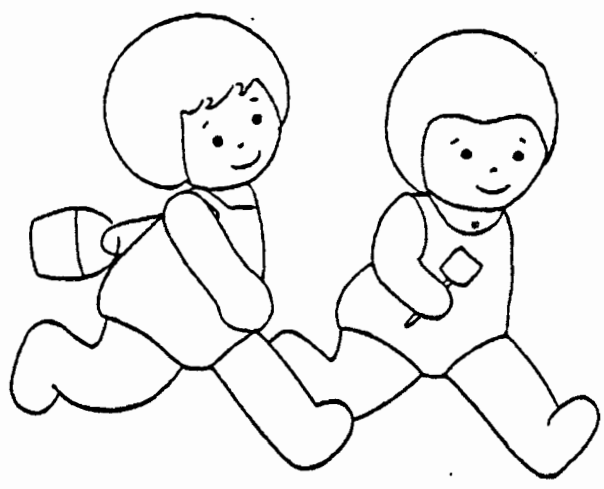
turns into a nice day. So you and your brother (sister) put on your swimsuits and run out to play on the beach.

You do you feel then?

How does your brother (sister) feel? 


\section{APPENDIX B}

SCRIPTS FOR THE THREE EXPERIMENTAL CONDITIONS

No-Mode1 (Control) Condition

(Second experimenter and child confederate leave room)

Ist Exp: I need a Kleenex... where did I put that box of Kleenex?

(Stands, bumps head on shelf.) Oh! Ouch! I bumped my head. (Sits down.) That hurt!

(Pause; 2nd exp. and child conf. re-enter)

2nd Exp: Sorry we took so long...Did anything happen while we were gone? (Pause for subject to respond. If no response:)

1st Exp: Well, I bumped my head, but it's all right now.

2nd Exp: Oh. (Game resumes)

\section{Modeling Condition}

(Second experimenter leaves room. Same injury and need verbalization.)

Child C: (Stands, goes to Ist Exp.) Are you all right? I hope it gets better soon. (Continue as before)

\section{Modeling P1us Induction Condition}

(Second experimenter leaves room. Same injury, need verbalization, and modeled response as before)

2nd Exp: Sorry I took so long...Did anything happen while I was gone?

1st Exp: We11, I bumped my head, but B__ made me feel better.

2nd Exp: B_ made you feel better? How did she do that?

1st Exp: She came over and asked if I was all right.

2nd Exp: Wow, $B$, that was really nice of you to make $M$ feel better. (To subject) I'll bet when you see somebody get hurt, you like to make them feel better too... I thought so.

Test of Sympathetic Behavior

(Finish game, piece is missing)

1st Exp: Hey, wait a minute...Part of the game is missing! 


\section{APPENDIX B (CONT'D.)}

2nd Exp: Oh dear...It's no fun to play a game when part of it's lost... We'd better find it! I know, maybe I dropped it in the hall. $\mathrm{M}$ _, why don't you and I look in the hall, and B_, you 10ok around the room while we're gone. (Experimenters leave room.)

Child C: Maybe it's in the trunk. (Goes to trunk, lifts lid.) No, it's not here. (Pretends to slam trunk on hand.) oh...I slammed my hand in the trunk, and it really hurts! (Pause, experimenters return, chance to report.) 
APPENDIX C

SCORING SYSTEMS 
SCORING SYSTEM FOR SYMPATHETIC BEHAVIOR

Score Category

I Essentially no response. No evidence of concern or sympathy. May notice trunk slam but directs attention elsewhere. No acknowledgement of injury or possibility of injury.

2 Child attends to the incident, verbally or non-verbally. May show evidence of subjective discomfort, must at least interest or intense awareness. May include a non-sympathetic response.

3 A verbal response acknowledging injury; may include association with child's own experience.

4 Verbal acknowledgement of injury, with remedy or admonition.

5 Verbal or physical offer of condolence, inquiry regarding the other's condition using such words as better, hurt, OK, all right, directed to the injured child.
Example of Response

Subject looked at child confederate, glanced at trunk, stared at child confederate, moved back toward chair, still watching her.

Subject looked at child confederate, said "Where'd it smash your hand?"

Subject moved toward child confederate, saying "You have to watch out, 'cause it hurts, it hurts."

Subject looked at child confederate, reached toward her, asked "Are you OK?" Subject approached child confederate, saying "OK, it's $\mathrm{OK}, \mathrm{B}$ we'11 just pack it up." Subjeck bent over to look at child confederate. 
SCORING SYSTEM FOR EXPLANATION OF AFFECT AND AWARENESS OF DISCREPANCY

\section{Explanation of Affect}

\section{Score $\underline{\text { Criteria }}$}

1 No response, irrelevant response, or response missing.

2 A response consistent with an emotion specified incorrectly. An unrealistic or fanciful response.

A response realistically consistent with the emotion correctly specified and all information given.

An inference going beyond the information given.
Example

"I don't know."

"Sad--because he might get lost" (DARK)

"If he walk in the dark he get scared--might be a cookie monster or a tiger" (DARK)

"Because he has a present-a new toy" (GIFT)

"Because she loves her grandma and she doesn't want her to go away" (GOODBYE)

\section{Awareness of Discrepancy}

1 No response, irrelevant response, or response missing.
Response showing awareness of the discrepancy between facial and story cues.

Attempt to explain discrepancy contradicts information given

Attempt to explain discrepancy focus on and can reconcile both facial and story cues
"I don't know," "And the bed?" (TIGER)

"I think she's happy again; I wonder why she's crying-because if it's her favorite king she'd probably be happy" (ICE CREAM)

"'Cause his mom got him the wrong king, that he didn't want" (ICE CREAM)

"Because the tiger's running after him and then he gets more running power." 
SCORING SYSTEM FOR INTERVENTION STRATEGIES

Question: What would you do if you saw someone $?$ (the mishap described in the story)

Score Criteria

1 Essentially no response. No acknowledgement of distress or injury or the possibility of injury.

2 Subject has attended to the distress or injury or possibility of injury, but offers nothing. Could include "don't know" answers or child's rejection of responsibility.

3 Verbal acknowledgement of distress or injury. May include association with child's own experience or evidence of empathic distress.

4. Some suggestion for action on behalf of the victim, remedy or admonition. Offer of help or attempt to get help, nonspecific inquiry. Must be clear that it is the other, not self, who suffers.

5 Offer of condolence, verbal or physical. Inquiry regarding other's condition, using such words as better, hurt, all right, OK, directed toward the victim. Active aid, clearly directed toward alleviating distress.
Example of Response

Child laughed or shrugged.

Subject gave slight laugh and said "I don't know" (CRYING LADY), "I would go home" (BROKEN LEG), "I didn't hurt herself--she did it by herself" (BROKEN LEG).

"Tipped over like that--on their knees" (WAGON), "I had a broken leg in my bed when I falled off my bed" (BROKEN LEG), "I'd cry too" (CRYING LADY) .

"I could pick 'em back up when they fall down" (WAGON), "I would go tell my--his father or mother" (WAGON), "I look in the house and see what happened."

"I would just go over and get something to wipe the tears off her--I'd just smile at her" (CRYING LADY), "Hug her" (CRYING LADY), "I would say, 'Hey! It's gonna be OK, man,'" (APPLE TREE), "I would help 'em get up, and run home and get a band-aid for 'em, and a washrag" (WAGON) 


\section{APPENDIX D}

\section{ANALYSIS OF VARIANCE SUMMARIES}

ANALYSIS OF VARIANCE SUMMARY FOR COMFORTING BEHAVIOR

\begin{tabular}{lccc} 
Source & df & MS & F \\
Experimental Condition (A) & 2 & 1.583 & .718 \\
Sex (B) & 1 & .003 & .001 \\
Age (C) & 1 & .029 & .013 \\
A x B & 2 & .393 & .178 \\
A x C & 2 & .400 & .181 \\
B X C & 1 & 3.337 & 1.513 \\
A x B X C & 2 & 2.528 & 1.146 \\
Error & 24 & 2.206 & \\
\hline
\end{tabular}


ANALYSIS OF VARIANCE SUMMARY FOR REPORTING

THE CHILD CONFEDERATE'S INJURY

\begin{tabular}{lrrr} 
Source & df & MS & F \\
\cline { 2 - 3 } Experimental Condition (A) & 2 & .127 & .211 \\
Sex (B) & 1 & .333 & .553 \\
Age (C) & 1 & 2.958 & $4.918^{*}$ \\
A X B & 3 & .109 & .181 \\
A X C & 3 & .188 & .313 \\
B X C & 1 & 2.003 & 3.331 \\
A X B X C & 2 & .123 & .205 \\
Error & 23 & .601 & \\
\hline
\end{tabular}

$* \mathrm{p}<.05$ 
APPENDIX E

ITEM ANALYSES 


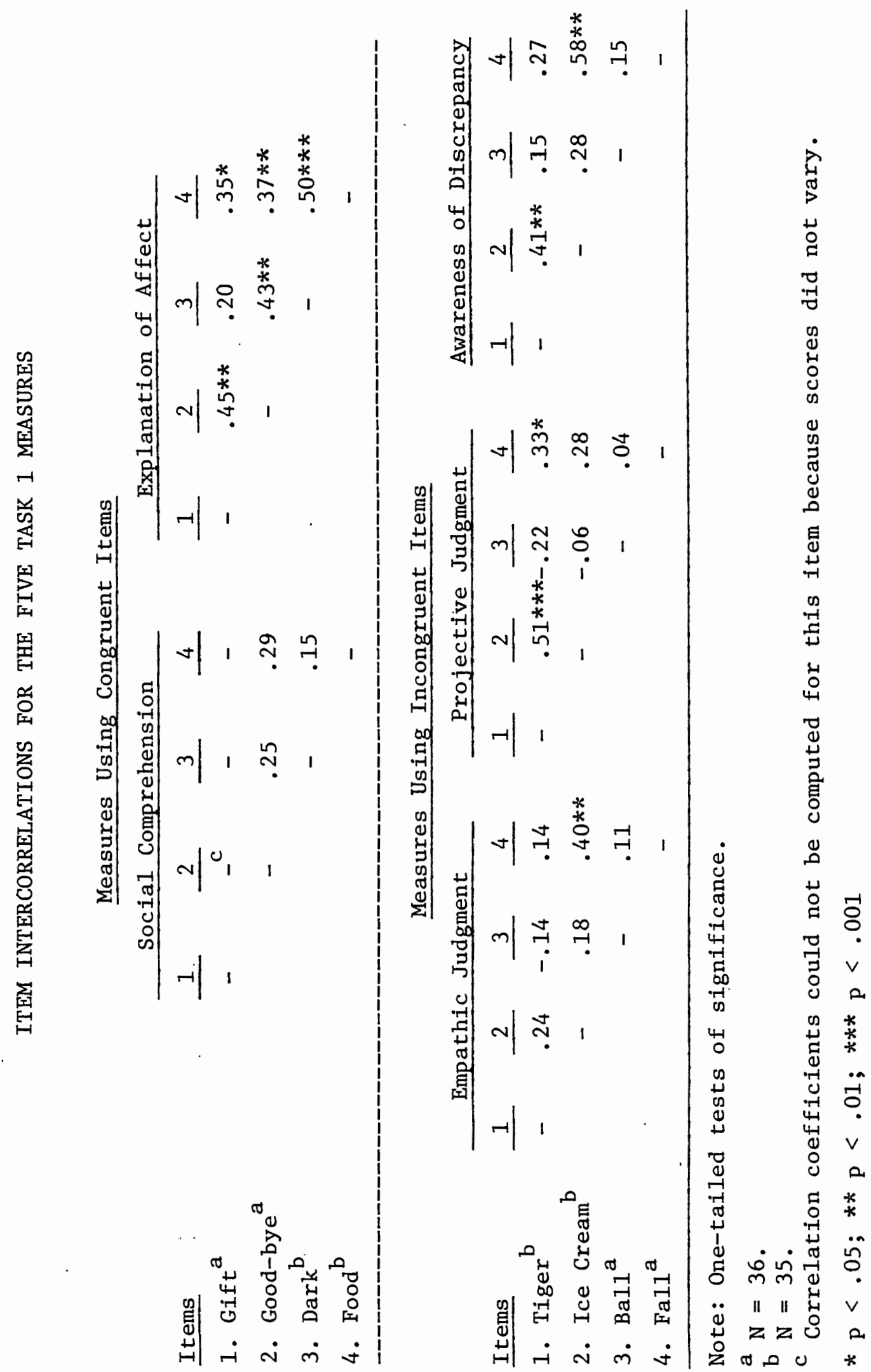




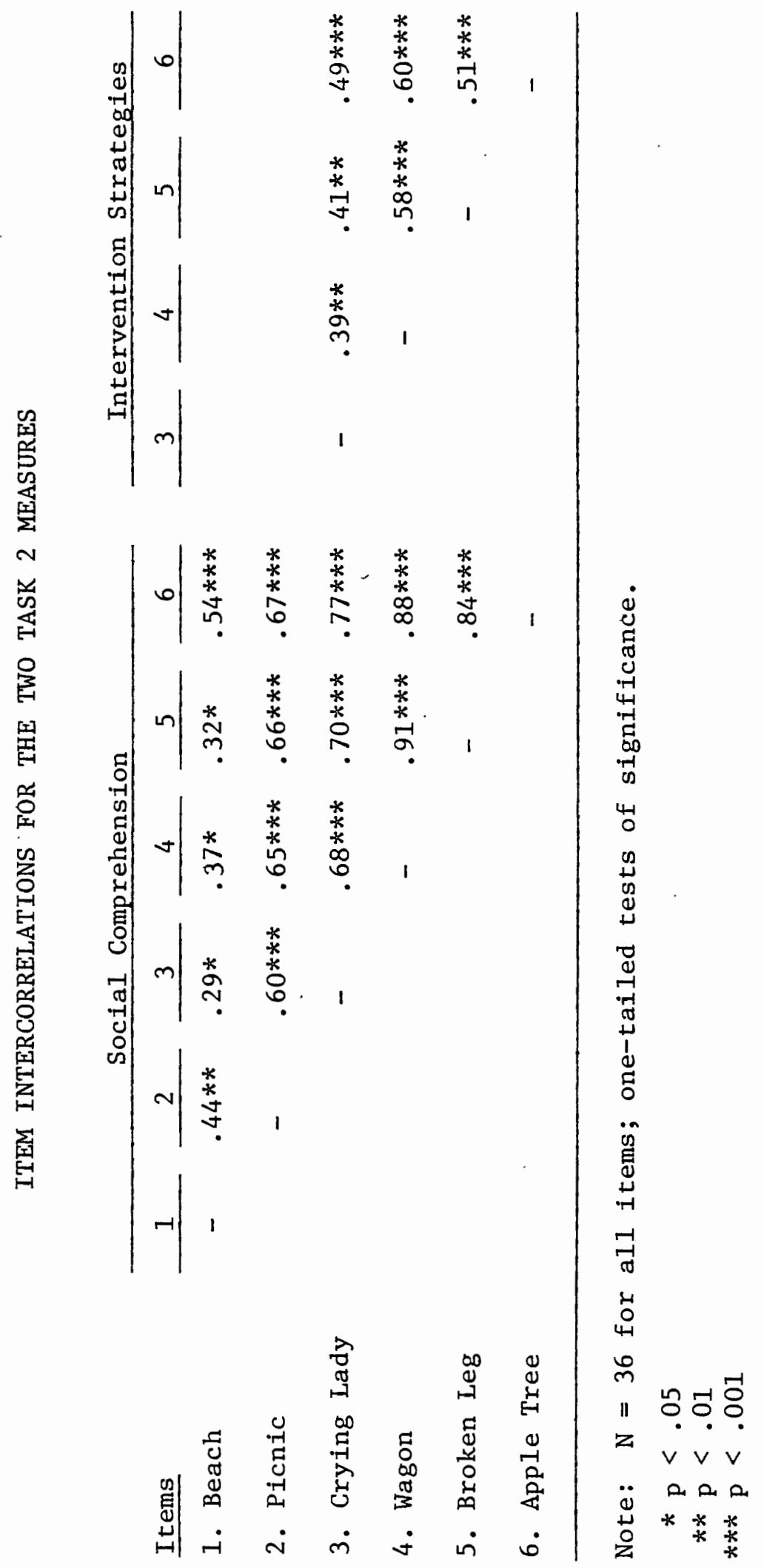




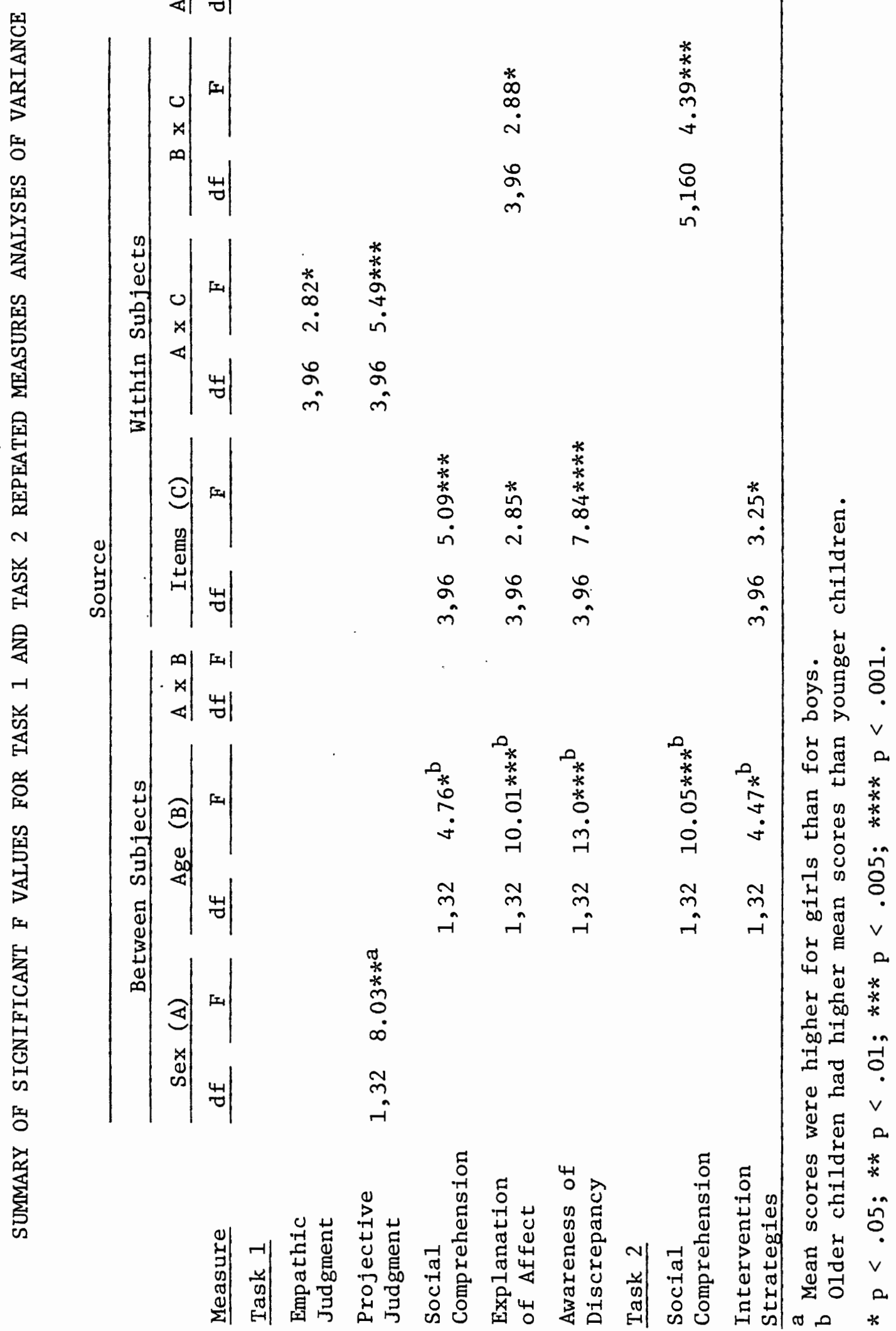

